\title{
The effect of age on a visual learning task in the American cockroach
}

\author{
Sheena Brown ${ }^{1}$ and Nicholas Strausfeld \\ Arizona Research Laboratories, Division of Neurobiology, University of Arizona, Tucson, Arizona 85721, USA
}

\begin{abstract}
Neuronal modifications that accompany normal aging occur in brain neuropils and might share commonalties across phyla including the most successful group, the Insecta. This study addresses the kinds of neuronal modifications associated with loss of memory that occur in the hemimetabolous insect Periplaneta americana. Among insects that display considerable longevity, the American cockroach lives up to $64 \mathrm{wk}$ and reveals specific cellular alterations in its mushroom bodies, higher centers that have been shown to be associated with learning and memory. The present results describe a vision-based learning paradigm, based on a modified Barnes maze, that compares memory in young (10-wk old), middle-aged (30-wk old), and aged adults (50-wk old). We show that not only is the performance of this task during the 14 training trials significantly decremented in aged cockroaches, but that aged cockroaches show significant impairment in successfully completing a crucial test involving cue rotation. Light and electron microscopical examination of the brains of these different age groups reveal major changes in neuron morphology and synaptology in the mushroom body lobes, centers shown to underlie place memory in this taxon.
\end{abstract}

Nonpathological aging of the brain is associated with a decline in cognitive function, which has been partially explained by changes affecting neuronal plasticity (Burke and Barnes 2006). The reduced learning and memory abilities evident in aged mammals have been correlated with cellular alterations within specific brain regions. Changes include alterations of dendritic branching and spine density (Duan et al. 2003), synapse number (De Groot and Bierman 1987; Geinisman et al. 1992), neuron number (West 1993), and synapse function (for review, see Barnes 1994). Invertebrate animal models have provided a relatively simple system in which to analyze the aging nervous system. The nematode Caenorhabditis elegans as well as the fruit fly Drosophila melanogaster have been used to identify genes involved in the aging process (Geanacopoulos 2004; Saitoe et al. 2005). Drosophila has also become an important model with which to assess the role in aging of oxidative stress, sleep consolidation, cardiac aging, and stem cell biology (for review, see Lim et al. 2006). The role of caloric restriction in slowing aging is also currently being investigated in Drosophila (Masoro 2006). However, thus far, there has been no study on a nonvertebrate system comparable to studies on mammals that associate age-related learning impairment to a specific brain center and changes that occur at the neuronal level within it.

The present work addresses this omission. Where might such a center be localized? And how would age-related alterations be manifested both at a behavioral and structural level? Behavioral assays that use olfactory and visual cues demonstrate that even restrained cockroaches can be assayed for associative as well as spatial learning and memory tasks using visual-directed antennal movements as behavioral indicators (Kwon et al. 2004; Lent and Kwon 2004) and that concomitantly display discrete changes in synaptic complexes of the mushroom bodies (Pintér et al. 2005). Vision-based behavioral assays (Mizunami et al. 1998a,b) based on the Morris water maze (Morris et al. 1982) demonstrate that cockroaches can be trained to learn and remember the location

\footnotetext{
'Corresponding author.
}

E-mail sheena@neurobio.arizona.edu; fax (520) 621-8282.

Article is online at http://www.learnmem.org/cgi/doi/10.1101//m.1241909. of hidden targets and that bilateral lesions of one of the mushroom body lobes abolishes place memory. If the mushroom bodies support or mediate place memory, then this is the brain region on which experiments should focus to determine the effects of aging on place memory.

For mammalian models, such as rodents, the Barnes maze paradigm (Barnes 1979) is ideal for testing age-related correlates in spatial learning and memory. Animals of various ages are trained to escape from a brightly lit, open platform surface into a small, dark, recessed box located underneath the platform, and their performances, correspondingly assessed. Like rodents, cockroaches actively avoid brightly lit open areas and are capable of learning places by virtue of visual cues. They live a long life and offer a small but accessible brain for correlative neuroanatomy. This robust system provides a model organism, in many ways analogous to the Murid rodents, in that they are omnivorous foragers, have urban ecologies, are crepuscular and nocturnal, and show parental care. Comparisons of this invertebrate model with mammals will determine if there are ubiquitous changes across phyla that occur with advancing age.

\section{Results}

\section{Behavioral observations}

From a random starting position at the center of the Barnes maze platform (Fig. 1; see Materials and Methods), individual cockroaches use different strategies to leave the brightly lit heated platform surface and successfully complete the maze task. Young adults (10-wk old) move very rapidly to the distal edge of the platform and use antennation as a search strategy to locate an exit from the platform surface. As will be described (refer to Fig. 2A), the percentage of 10 -wk-old adults that successfully learn the location of the escape tunnel increases from $70 \%$ at day 1 , to $83 \%$ at day 2. This completion success was consistent over successive trials (Figs. 2A and 3A). Middle-aged adults (30-wk old) do not move rapidly from their starting point, but stay within this central location for 10 to $20 \mathrm{sec}$, moving their antennae, head, and body to different orientations toward the wall (and therefore toward the visual cues and tunnels) enclosing the platform. Their completion 

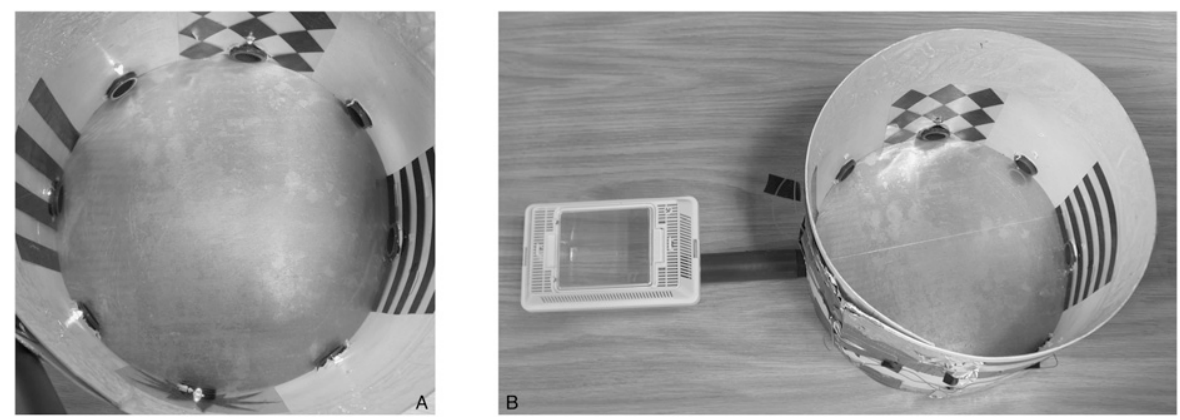

Figure 1. (A) The modified Barnes maze (Barnes 1979) consisted of a 12-inch circular aluminum platform enclosed by a 10-inch wall. (B) Spaced equidistant around the wall were eight potential escape tunnels, with only one tunnel leading from the platform into a small cage. Overhead heat and light were used to motivate the animals to locate the correct escape tunnel within a maximum 3-min time frame. Visual cues were placed around the walls to aid location of the escape tunnel. Ethanol was used to clean all surfaces between each animal.

success and completion consistency (described below; Figs. 2B and $3 \mathrm{D})$ indicates that behavior of this age group is being divided bimodally, with some individuals comparable to success rates achieved by 10 -wk-old adults (individuals completing the task in $80 \%$ or more of the trials; Fig. 3D), while other individuals are considerably less successful (individuals completing the task in $60 \%$ or less of the trials; Fig. 3D). Aged adults (50-wk old) at the start of the test remain in the middle of the platform center for 1 to 2 min before moving toward the enclosing wall. Most do not successfully complete the task (34\% successfully completed the task at day 2 , and $46 \%$ at day 14 ; Fig. 2C), while those that do show little consistency over successive trials $(37.7 \% \pm 33.71 \%$ mean task completion for all individuals over all trials; Fig. 3G). The behavioral bimodal distribution within this aged group is more pronounced than that of the 30-wk-old adults, with significantly fewer individuals capable of completing the task consistently (Fig. 3G).

\section{Deficits in maze completion associated with increasing age}

\section{Maze completion}

There is a significant impairment in the ability of older cockroaches to successfully complete the maze task. In those groups provided with visual cues $(10 \mathrm{~W}+, 30 \mathrm{~W}+, 50 \mathrm{~W}+), 10$-wk-old animals were significantly more successful at completing the maze than both 30-wk-old and 50-wk-old animals (Mann-Whitney $U=$ 68,866.0, $Z=-5.767, P<0.001$; Mann-Whitney $U=41,314.50, z=$ $-14.794, P<0.001$, respectively). Thirty-week-old animals were also significantly more successful than the 50-wk-old animals (Mann-Whitney $U=58,887.50, z=-9.924, P<0.001$ ). The decline in ability to complete the task therefore begins sometime after $10 \mathrm{wk}$ of age, further declining through to $50 \mathrm{wk}$ of age, with the middleaged group (30-wk old) intermediate in completion abilities.

In animals not provided with visual cues $(10 \mathrm{~W}-, 30 \mathrm{~W}-$, $50 \mathrm{~W}-$ ), 10-wk-old adults were significantly more successful at completing the maze than both 30 -wk-old and 50-wk-old adults (Mann-Whitney $U=12,691.00, z=-4.076, P<0.001$; MannWhitney $U=7287.00, z=-3.431, P=0.001$, respectively), with rates of maze completion not significantly different between 30wk-old and 50-wk-old adults (Mann-Whitney $U=8894.5, Z=$ $-0.79, P=0.937)$. These data suggest that in the absence of proximal visual cues, 10 -wk-old adults are more able to detect and make effective use of distant visual cues in successfully locating the escape tunnel, than either of the older age groups.

Regression analysis within experimental groups of the 14 training trials (Fig. 2) showed that 10-wk-old animals provided with visual cues $(10 \mathrm{~W}+, P=0.036), 10$ wk-old animals not provided with cues (10W-, $P=0.006)$, and 50-wk-old animals not provided with visual cues (50W-, $P=0.038$ ) significantly improve their rates of maze completion over successive training trials. This suggests that these groups were able to improve rates of successful maze completion based on previous experience of the task. The 10wk-old group provided with visual cues also shows little trial-to-trial variation in completion rates, indicating that while most individuals within this group were able to complete the task well from Trial 1 , there was still significant improvement of the task with experience. While 10-wkold and 50-wk-old animals not provided with visual cues also significantly improved over successive trials, when visual cues were provided during the maze task, animals in the 10-wk-old and 30-wk-old age groups were significantly more successful in completing the maze task than those animals tested without visual cues (10-wk-old, Mann-Whitney $U=28,973.00, z=-5.451, P<0.001$; 30-wk-old, Mann-Whitney $U=28,381.50, z=-5.515, P<0.001)$. These data indicate that as more visual information is provided, the young and middle-aged animals are able to integrate this information successfully to aid navigation. In the 50-wk-old group, those animals without visual cues show significantly higher rates of maze completion than those provided with visual cues (MannWhitney $U=19,130.00, z=-2.004, P=0.045)$. At visual cue rotation (Fig. 4G-I; Trial 15, $10 \mathrm{~W}+, 30 \mathrm{~W}+, 50 \mathrm{~W}+$ ), percentage completion rates were consistent with those achieved at day 14 in all age groups $(10 \mathrm{~W}+, 96 \%$ day $14,96 \%$ day $15 ; 30 \mathrm{~W}+, 80 \%$ day 14 , $85 \%$ day $15 ; 50 \mathrm{~W}+, 46 \%$ day $14,40 \%$ day 15$)$. In the 10 -wk-old group, the same individual did not complete the task on either day 14 or 15 . This is in sharp contrast to the 30-wk-old group, where only $75 \%$ of those that completed the task successfully on day 14 also completed the task on day 15 . In the 50-wk-old group, $90 \%$ of those that completed the task on day 14 also completed the task on day 15. Issues regarding individual consistency are addressed below.

In all age groups, all animals (those that were provided with visual cues, and those that were not) showed significantly higher rates of maze completion than the vision-control groups, 10-wkold, 30-wk-old, and 50-wk-old animals that had their eyes and ocelli concealed with paint (Kruskal-Wallis test, 10-wk old $\chi^{2}=$ 253.58, df $=2, P<0.001 ; 30$-wk old, $\chi^{2}=208.34, \mathrm{df}=2, P<0.001$; 50 -wk old, $\chi^{2}=27.050, \mathrm{df}=2, P<0.001$ ). Rates of maze completion of animals with painted eyes did not differ significantly between the age groups (Kruskal-Wallis test, $\chi^{2}=2.889, \mathrm{df}=2, P=0.236$ ). From these data, we determine that the visual cues play a significant role in assisting individuals from all age groups in completing the task.

\section{Consistency}

While rates of maze completion allow us to analyze success at the group level, completion consistency allows us to analyze the success of individuals within these groups. Completion consistency is defined as the number of trials completed successfully out of the total 14 trials attempted by each individual. This was converted to a percentage and is shown for each group (Fig. 3). The trends shown by the data clearly reveal that as age increases individuals are less likely to complete the maze task consistently over the total number of trials. While 10-wk-old adults provided with visual cues successfully completed the maze task in $87.8 \%$ of their trials, 50 -wk-old adults provided with visual cues successfully completed the maze 
task in only $37.7 \%$ of their trials. In the 30 -wk-old group provided with visual cues, just over half of the animals are still completing the maze task in $80 \%$ or more of their trials, while the remainder of the
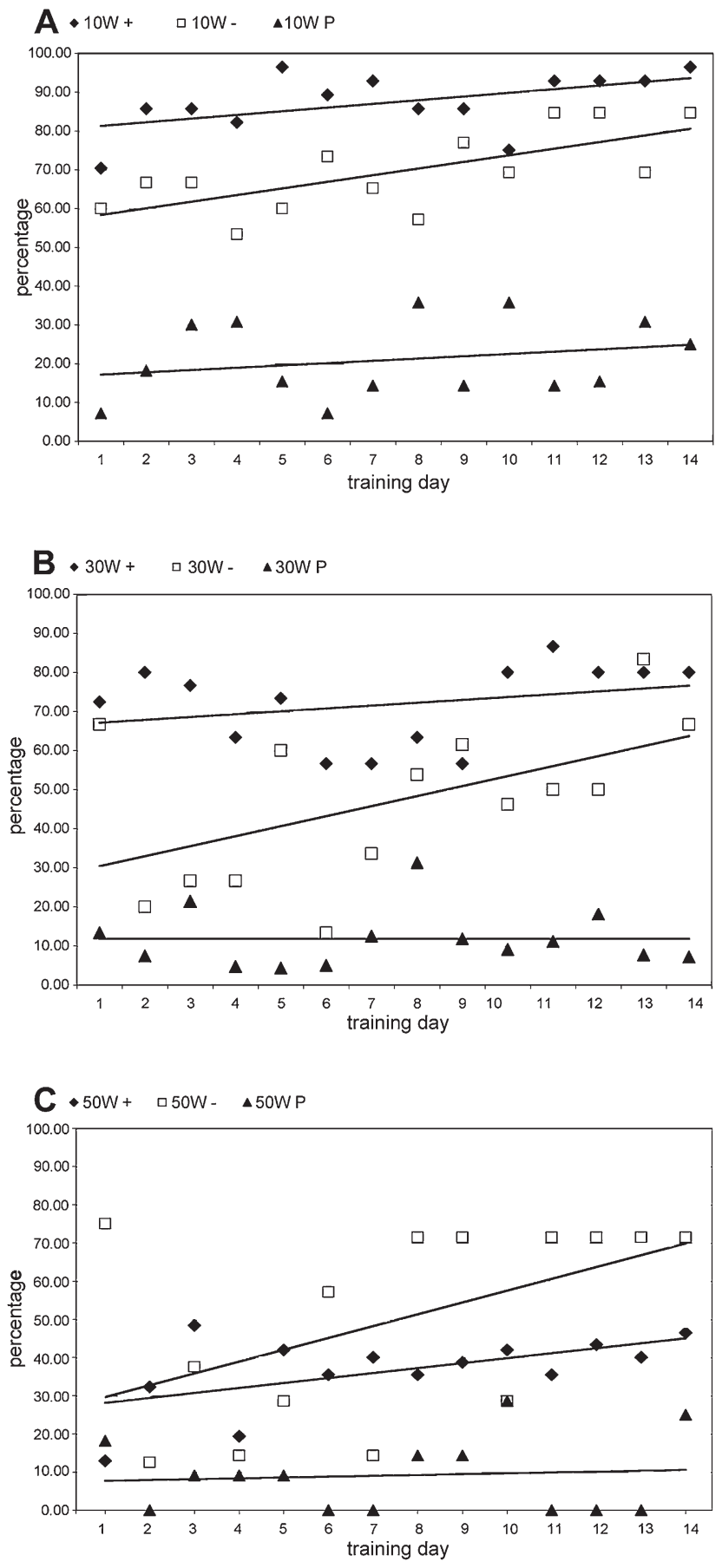

\begin{tabular}{|lcclll|}
\hline D Age & Group & $\mathbf{N}$ & Regression Equation & $\boldsymbol{R}^{2}$ & $P$-value \\
$10 \mathrm{~W}$ & + & 28 & $\mathrm{Y}=0.9486 \mathrm{x}+80.310$ & 0.2664 & 0.036 \\
$10 \mathrm{~W}$ & + & 13 & $\mathrm{Y}=1.7089 \mathrm{x}+56.583$ & 0.4800 & 0.006 \\
$10 \mathrm{~W}$ & $\mathrm{P}$ & 14 & $\mathrm{Y}=0.5894 \mathrm{x}+16.584$ & 0.0603 & 0.398 \\
$30 \mathrm{~W}$ & + & 30 & $\mathrm{Y}=0.7296 \mathrm{x}+66.367$ & 0.0856 & 0.219 \\
$30 \mathrm{~W}$ & - & 12 & $\mathrm{Y}=2.5618 \mathrm{x}+27.819$ & 0.2761 & 0.540 \\
$30 \mathrm{~W}$ & $\mathrm{P}$ & 14 & $\mathrm{Y}=0.0782 \mathrm{x}+13.359$ & 0.0018 & 0.887 \\
$50 \mathrm{~W}$ & + & 29 & $\mathrm{Y}=3.0926 \mathrm{x}+26.550$ & 0.2571 & 0.064 \\
$50 \mathrm{~W}$ & - & 8 & $\mathrm{Y}=1.3046 \mathrm{x}+26.766$ & 0.3105 & 0.038 \\
$50 \mathrm{~W}$ & $\mathrm{P}$ & 10 & $\mathrm{Y}=0.2148 x+7.5032$ & 0.0083 & 0.757 \\
\hline
\end{tabular}

group are only completing the task in $30 \%-60 \%$ of the trials. In the 50-wk-old group, this split becomes further emphasized, with no individuals completing the task in $100 \%$ of the trials, $31 \%$ of the tested population completing the maze task successfully in $80 \%-$ $90 \%$ of the trials, and $44 \%$ of the tested population completing the task in $<30 \%$ of their total trials. In the groups not provided with visual cues, the trends are similar, with the 30 -wk-old and 50-wk-old groups not performing as consistently as the 10-wk-old group. Maze completion consistency was clearly reduced in all age groups where vision had been obscured (Fig. 3C,F,I). A comparison across age groups shows that the percentage of individuals successfully completing the maze task consistently over the 14 trials was significantly greater in the 10 -wk-old group provided with visual cues $(10 \mathrm{~W}+)$, than in the 10-wk-old group not provided with visual cues (10W-) and in the 30-wk-old group provided with visual cues $(30 \mathrm{~W}+)(F=$ 21.616, $\mathrm{df}=8, P<0.001$ ).

\section{Maze completion time and number of errors}

Further analysis of only those individuals that completed the maze task and that were provided with visual cues $(10 \mathrm{~W}+, 30 \mathrm{~W}+, 50 \mathrm{~W}+)$ revealed crucial differences between the age groups (Fig. 4). Maze completion time was calculated for each individual after seven training trials (day 7), after 14 training trials (day 14), and on day 15 when the cues were rotated $90^{\circ}$ clockwise, to establish if animals performed the task faster having gained experience over the successive training trials and to determine any effect of cue rotation on task completion.

Ten-week-old animals were on average completing the task in $<1$ min by Trial 7, and this completion time did not change significantly at day 14 or day 15 (Fig. 4 A; $F=0.593$, df $=2, P=$ 0.555 ). The 30 -wk-old animals showed a significant decrease in their mean maze completion time from day 7 to day 15 (Fig. 4B; $F=2.966, \mathrm{df}=2, P=0.045)$, and on day 7 had significantly longer mean maze completion times than 10-wk-old animals at day 7 ( $t=-2.847, \mathrm{df}=56, P=0.006)$. The 50-wk-old animals took, on average, twice as long (mean $=2.09 \mathrm{~min}$ ) as the 10 -wk-old animals to complete the maze task after seven training trials. This time did not significantly alter throughout the remaining training trials (Fig. 4C; $F=0.779$, $\mathrm{df}=2, P=0.462$ ). After 14 training trials, both 10-wk-old and 30-wk-old animals were completing the task in significantly shorter times than the 50-wk-old animals $(F=4.317$, $\mathrm{df}=2.78, P=0.017)$. At day 15 , when the visual cues had been rotated, the 10 -wk-old and 30 -wk-old animals were completing the task within the same time frame, with both groups completing the task significantly faster than the 50-wk-old group $(F=10.844$, $\mathrm{df}=2.81, P<0.001$ )

It was hypothesized that if animals learn to associate the visual cues with the location of the correct escape tunnel, the

Figure 2. Percentage of animals within each group that completed the maze task within the 3-min time period. In all age groups, those animals provided with visual cues showed significantly higher rates of maze completion than those animals not provided with visual cues (MannWhitney test: $10 w k, P<0.001 ; 30 w k, P<0.001 ; 50 w k, P=0.045)$. A significant increase in animals successfully completing the maze over all training trials was seen in 10 -wk-old animals provided with visual cues $(P=$ $0.036), 10$-wk-old animals not provided with cues $(P=0.006)$, and 50 wk-old animals provided with visual cues $(P=0.038)$. ( $A$ ) Ten-week-old adults provided with visual cues $(10 \mathrm{~W}+), 10$-wk-old adults not provided with visual cues ( $\square 10 \mathrm{~W}-$ ), and 10-wk-old adults with eyes and ocelli painted ( $\mathbf{\Lambda}$ 10W P). (B) Thirty-week-old adults provided with visual cues $(\checkmark 30 \mathrm{~W}+), 30$-wk-old adults not provided with visual cues $(\square 30 \mathrm{~W}-$ ), and 30-wk-old adults with eyes and ocelli painted ( $\Delta$ 30W P). (C) Fiftyweek-old adults provided with visual cues $(50 \mathrm{~W}+)$, 50-wk-old adults not provided with visual cues ( $\square 50 \mathrm{~W}-$ ), and 50 -wk-old adults with eyes and ocelli painted $(\boldsymbol{\Delta} 50 \mathrm{~W} P)$. (D) Sample size $(N)$, regression equations, $R^{2}$ values, and $P$-values are shown for all groups analyzed. 

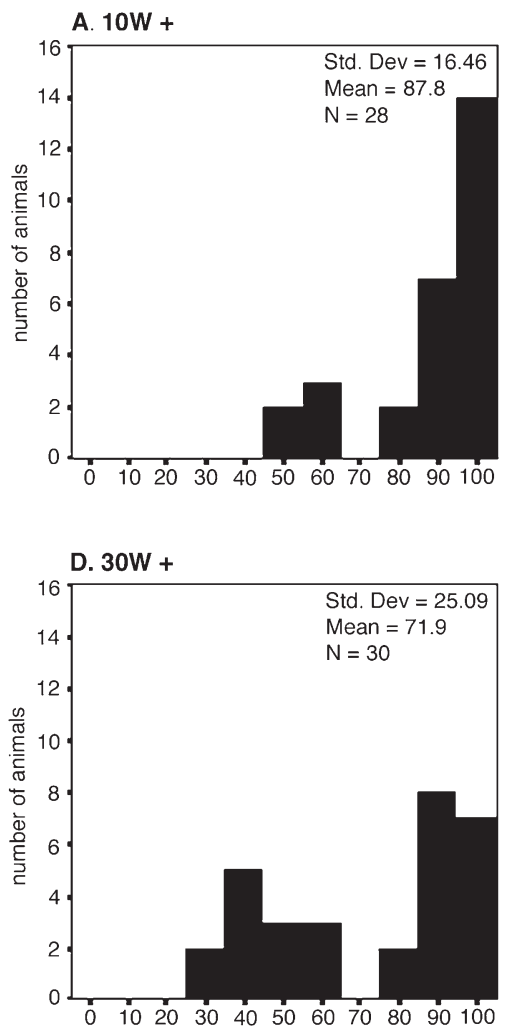

G. $50 \mathrm{~W}+$

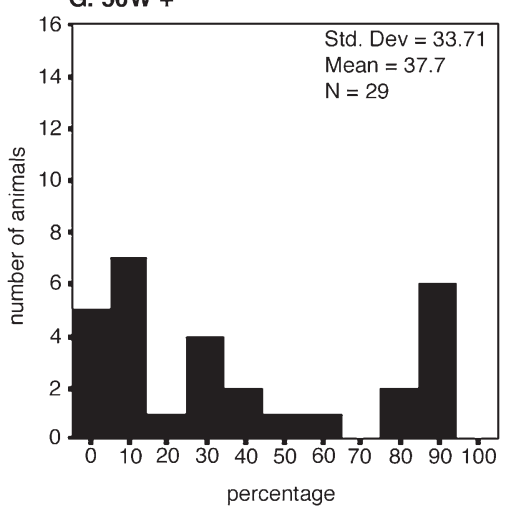

B. $10 \mathrm{~W}$ -

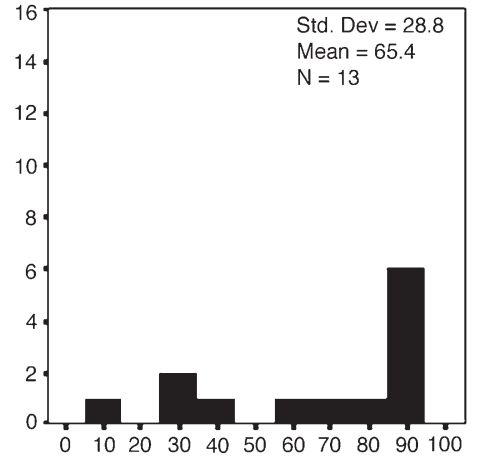

E. 30 W -

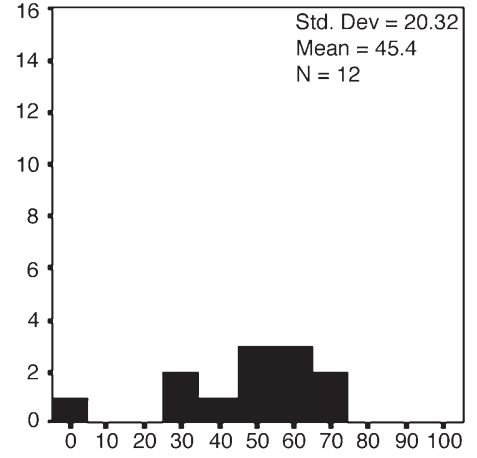

H. 50W -

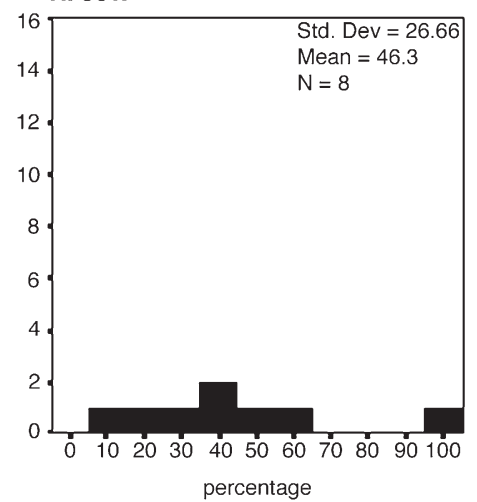

C. 10W P
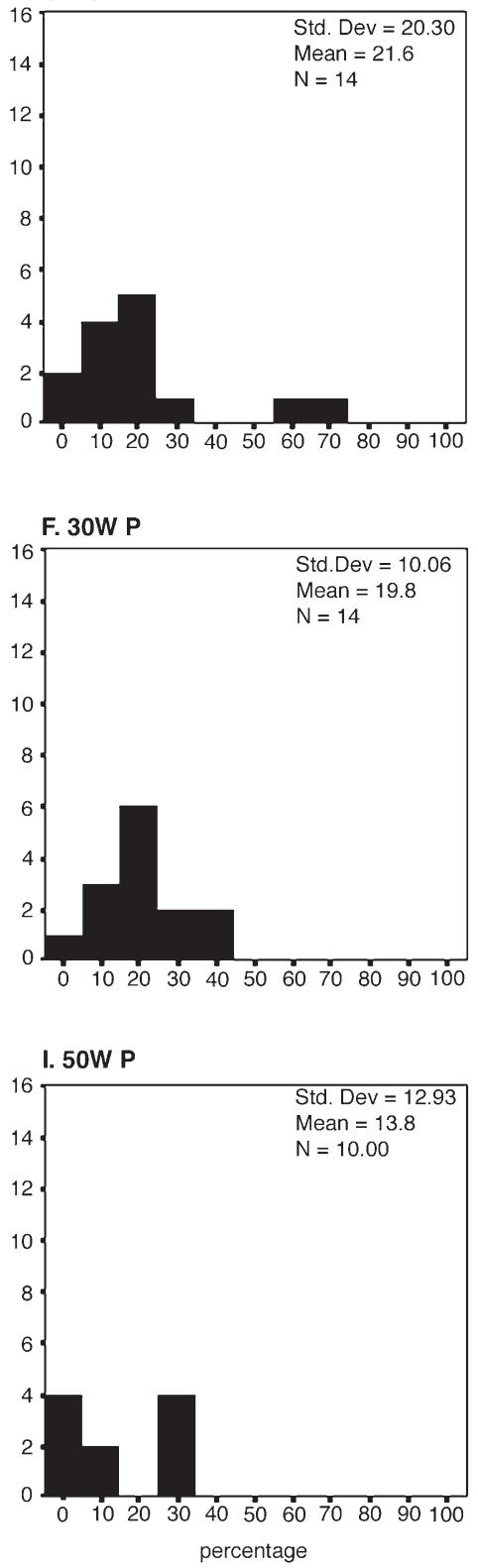

Figure 3. Consistency of individuals successfully completing the maze over the 14 training trials. Consistency was significantly greater in the 10 -wk-old group provided with visual cues, the 10-wk-old group not provided with visual cues, and in the 30-wk-old group provided with visual cues, than in all other groups tested (one-way ANOVA, $\mathrm{df}=8, F=21.616, P<0.001) .(A, D, G)$ Ten-week-old, 30-wk-old, and 50-wk-old animals provided with visual cues, respectively. $(B, E, H)$ Ten-week-old, 30-wk-old, and 50-wk-old animals not provided with visual cues, respectively. (C, F, I) Ten-week-old, 30-wk-old, and 50-wk-old animals with painted eyes and ocelli, respectively. Standard deviations, means, and sample sizes are shown for each group analyzed.

number of errors (the number of times an individual tried to leave the maze platform via an incorrect tunnel) should decrease with experience but would likely increase when the cues were rotated owing to the learned association with the cue that had previously been associated with the correct escape tunnel. The 10-wk-old animals exhibited the same number of errors throughout the 14 training trials, but they increased significantly on cue rotation (Fig. 4D; $F=6.444$, df $=2, P=0.003$ ). The 30 -wk-old animals showed a trend of decreased errors from day 7 to 14 , with a significant increase in the number of errors on cue rotation at day 15 (Fig. $4 \mathrm{E} ; F=3.929$, df $=2, P=0.023$ ). In the 50 -wk-old group, the number of errors did not alter significantly between any of the trials (Fig. 4F; $F=0.794, \mathrm{df}=2, P=0.455$ ), but did show an increasing error trend at cue rotation. On day 15, the mean number of errors was not significantly different between any of the age groups $(F=0.193, \mathrm{df}=2, P=0.825)$.

Behavioral strategies used for successful task completion Observation of the activity patterns of individuals as they performed the maze task emphasized differences between the age groups. The middle-aged animals (30-wk old) moved about the maze platform more hesitantly than the 10 -wk-old adults. A greater proportion of the 50-wk-old adults did not complete the maze task, thereby highlighting a distinct split in the behavioral 
A. 10W Adults

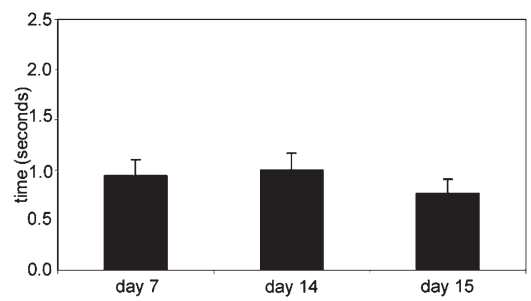

B. 3ow Adults

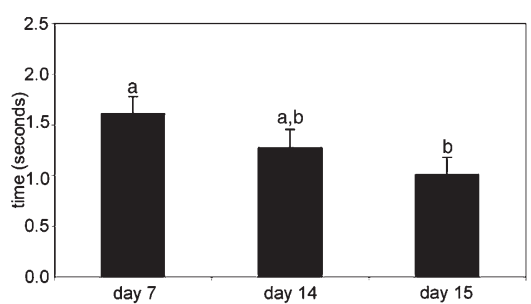

C. 50w Adults

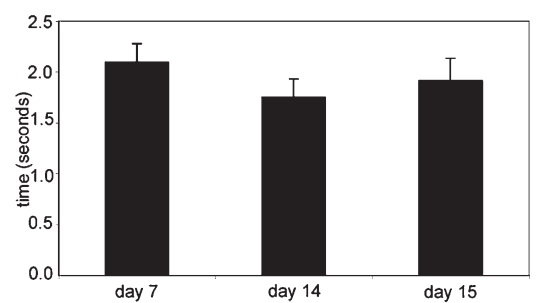

D. 10W Adults

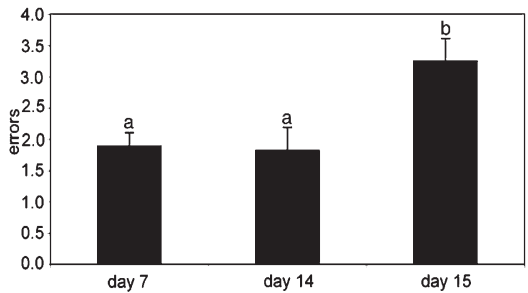

E. sow Adults

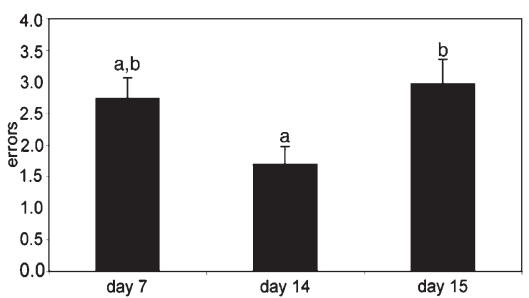

F. sow Adults

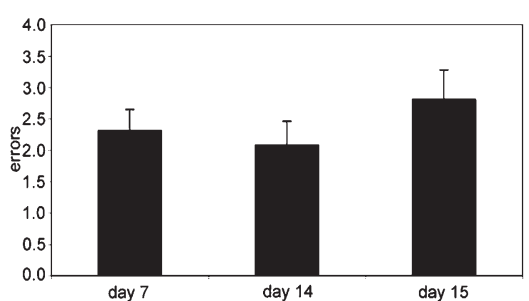

G. 10w Adults

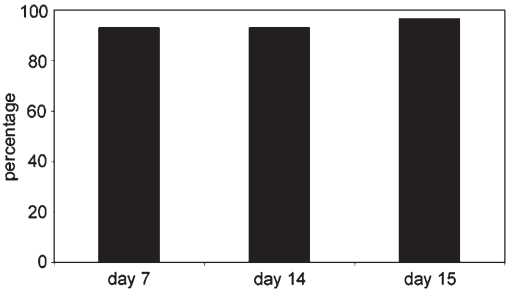

H. 3ow Adults

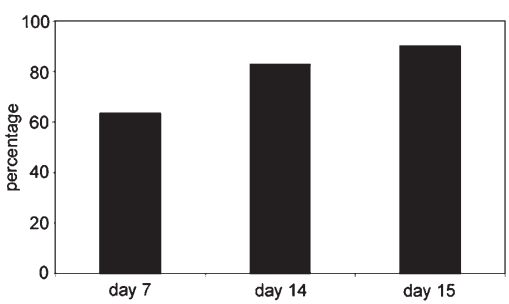

I. sow Adults

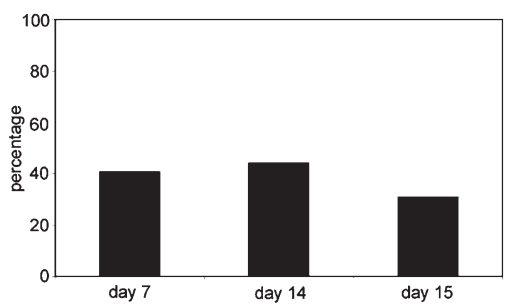

Figure 4. ( $A-C)$ Maze completion time, $(D-F)$ the number of errors made by an individual per trial, and (G-l) the percentage of successful maze completion are shown for 10-wk-old, 30-wk-old, and 50-wk-old adults that had been provided with visual cues. Three time points are shown; day 7 is data collected on the seventh day of training, day 14 is data collected on the fourteenth (and last) day of training, and day 15 is data collected at visual cue rotation.

capabilities within this age group into those that could sometimes or often complete the maze task and those that seldom or never completed the task. From the logistic regression (Table 1), several measured parameters (individually and interactively) were shown to be significant factors associated with whether animals successfully completed the maze task, these factors being age, group, and trial number, as well as path length, still time, and average speed. By plotting still time with path length (Fig. 5A-F), the data clearly separated into two clusters as group age increased-those animals that completed the maze task spending less time standing still and having a tendency for having shorter path lengths, and those animals that did not complete the task, displaying longer still times and longer path lengths. The youngest adults tested here (10W) moved quickly with no apparent initial directional decision; the middle-aged adults (30W) were more hesitant with their movements; while the aged adults (50W) often remained still for long periods of time before moving (Fig. 5). Behavioral responses, wherein different individuals use quite differing tactics, can be interpreted as partly a consequence of the very unnatural conditions of the experimental setup: a brightly lit and heated arena that, anthropocentrically, we would consider stressful.

\section{The impact of visual cues on successful task completion}

The role of the visual cues as aids for cockroaches of all ages to learn the Barnes maze paradigm is clearly shown by group completion rates (Fig. 2) and individual completion consistencies (Fig. 3). Representing the parameters path length and still time as a mean per age and treatment group $( \pm \mathrm{SE})$, the three tested groups (+cues, -cues, painted eyes) separate out into distinct clusters (Fig. 6), further illustrating behavioral differences between groups able to use the provided visual cues and those unable to see visual cues. Path length is remarkably similar across all age groups provided with visual cues (Fig. 6A; $F=1.827$, df $=2.1236, P=0.161$ ) (also

Table 1. Wald statistics for type 3 GEE analysis

\begin{tabular}{lcrc}
\hline Source & df & $\chi^{2}$ & $\operatorname{Pr}>\chi^{2}$ \\
\hline Age & 2 & 6.66 & $0.0358^{*}$ \\
Group & 2 & 18.64 & $<0.0001^{*}$ \\
Age*Group $_{\text {Trial ID }}$ & 4 & 4.47 & 0.3460 \\
Trial ID*Age & 1 & 8.64 & $0.0033^{*}$ \\
Trial ID*Group & 2 & 1.73 & 0.4215 \\
Trial ID*Age*Group & 2 & 0.39 & 0.8211 \\
Path length & 4 & 5.72 & 0.2211 \\
Path length*Age & 1 & 47.05 & $<0.0001^{*}$ \\
Path length*Group & 2 & 2.64 & 0.2670 \\
Path length*Age*Group & 2 & 2.15 & 0.3407 \\
Still time & 4 & 16.07 & $0.0029^{*}$ \\
Still time*Age & 1 & 227.85 & $<0.0001^{*}$ \\
Still time*Group & 2 & 5.22 & 0.0737 \\
Still time*Age*Group & 2 & 8.79 & $0.0123^{*}$ \\
Average speed & 4 & 10.94 & $0.0272^{*}$ \\
Average speed*Age & 1 & 0.27 & 0.6022 \\
Average speed*Age*Group & 2 & 0.57 & 0.7523 \\
& 4 & 10.09 & $0.0390^{*}$ \\
\hline
\end{tabular}

Asterisks in last column denote significant factors in determining whether animals successfully completed the maze. 
A

10W Adults - day 14

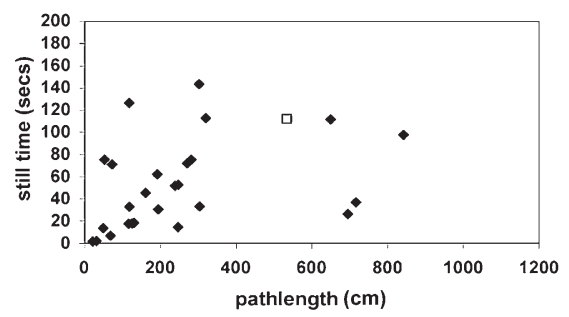

B

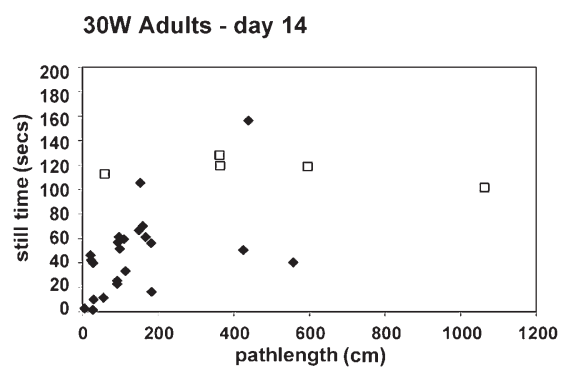

C

50W Adults - day 14

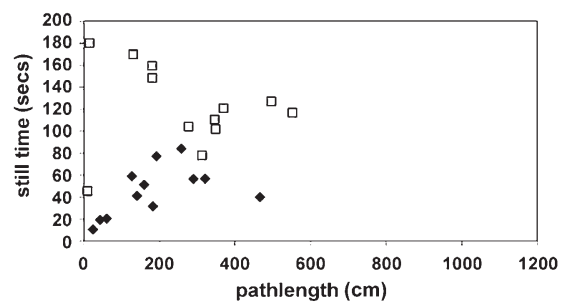

D

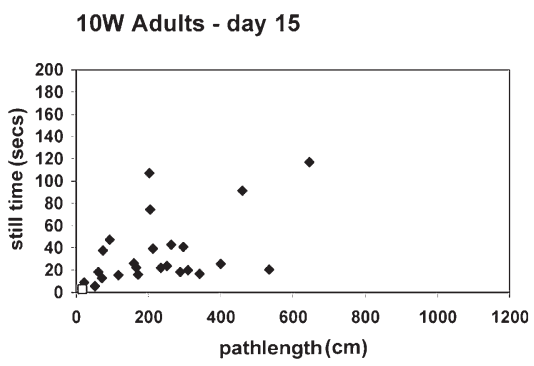

$\mathbf{E}$

30W Adults - day 15

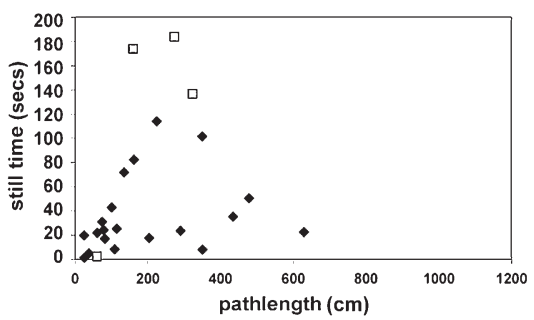

$\mathbf{F}$

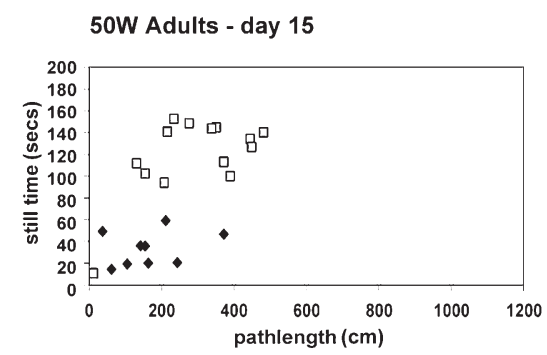

- complete

¿ incomplete

Figure 5. Path length and still time are predictors of maze completion. $(A-C)$ From those individuals provided with visual cues, path length plotted with still time for 10-wk-old, 30-wk-old, and 50-wk-old adults at day 14 of training, and $(D-F)$ at day 15 (cue rotation). ( $)$ Those animals that successfully completed the task can be compared to ( $\square$ ) those that did not successfully complete the task Differences in plots of still time versus path length are particularly noticeable in the 50 -wk-old age group, where the rates of task incompletion are highest. Animals in this age group that complete the task have a shorter still time and path length than those that do not. This is particularly evident at day 15 , when the visual cues were rotated.

refer to histograms in Fig. 6B) and across all age groups not provided with visual cues $(F=0.864$, $\mathrm{df}=2.462, P=0.422)$. However, within the painted eye group (see Materials and Methods), 10-wk-old animals had significantly shorter path lengths than 30-wk-old and 50-wk-old animals $(F=7.737, \mathrm{df}=2.603, P<$ 0.001 ), suggesting that the younger animals are able to somehow compensate for their lack of vision during the execution of the task. Path length between treatment groups (+cues, -cues, painted eyes) is significantly shorter in animals provided with visual cues regardless of age $(10 \mathrm{~W}, F=7.858, \mathrm{df}=2.772, P<0.001 ; 30 \mathrm{~W}, F=$ 63.945, $\mathrm{df}=2.903, P<0.001 ; 50 \mathrm{~W}, F=24.007, \mathrm{df}=2.626, P<0.001$ ).

Analysis of still times showed significant differences both within and between age groups. In animals provided with visual cues, 10-wk-old animals had significantly less still time than both 30-wk-old and 50-wk-old animals $(F=91.797$, df $=2.1236, P<$ $0.001)$. In animals not provided with visual cues, 10 -wk-old ani- mals also had significantly less still time than both 30-wk-old and 50-wk-old animals $(F=6.172$, df $=2.462, P=0.002)$. However, no significant differences in still time were found between 10-wk-old, 30wk-old, and 50-wk-old animals with painted eyes $(F=1.547, \mathrm{df}=2.603, P=$ 0.214 ). Between groups (+ cues, - cues, painted eyes), 10-wk-old animals provided with visual cues had significantly less still time than those not provided with visual cues and those with painted eyes $(F=99.815, \mathrm{df}=2.772, P<0.001)$. In both the 30-wk-old and 50-wk-old groups, those provided with visual cues and those not provided with visual cues had significantly less still time than those with painted eyes $(30 \mathrm{~W}, F=40.878$, df $=$ $2, P<0.001 ; 50 \mathrm{~W}, F=9.250, \mathrm{df}=2.626$, $P<0.001)$. Histograms of path length (Fig. 6B) and still time (Fig. 6C) illustrate and compare the dramatic range of data points for these parameters between animals provided with visual cues and those with painted eyes.

\section{Morphology of beta lobe Kenyon cells}

Several lines of evidence suggest that the mushroom bodies, traditionally thought to mediate olfactory learning and memory (Davis 2005), also mediate place memory. Studies by Mizunami et al. (1998b) demonstrate that the beta lobe of one mushroom body is necessary for memorizing a hidden target, an invisible cold area, the location of which is determined by its position relative to remote visual stimuli. Cues that are not remote, but that are indicative of location, such as the heat-box paradigm used on walking flies (Zars 2000) that provides an either-or choice, or, similarly, directional conditioning of flying flies (Wolf et al. 1998), can be learned in the complete absence of mushroom bodies, however. Similarly, in a learning arena in which the cold area is visible to the animal, lesioning of both mushroom bodies does not abolish its ability to locate this target (Mizunami et al. 1998b). Observations of centrophobic spatial behavior of Drosophila (Besson and Martin 2005) also suggest that intact mushroom bodies are necessary for this behavior, although in principle, this taxis does not require place memory. If mushroom bodies underlie place memory using far-field cues and if changes occur within synaptic networks that are consistent with age-related cognitive decline, then the mushroom body lobes are obvious areas of interest.

Mushroom bodies comprise systems of parallel fibers provided by their intrinsic neurons, the Kenyon cells (Fig. 7A). These cells receive along their lengths multisensory inputs from other cerebral areas, and their outputs, which reach parts of the protocerebrum, analogous to motor cortices of mammalian brains, respond in a context-dependent manner to sensory stimuli (Li and Strausfeld 1997, 1999). Golgi analyses of Kenyon cells in the beta lobe (Figs. 8 and 9) show two major specializations that 


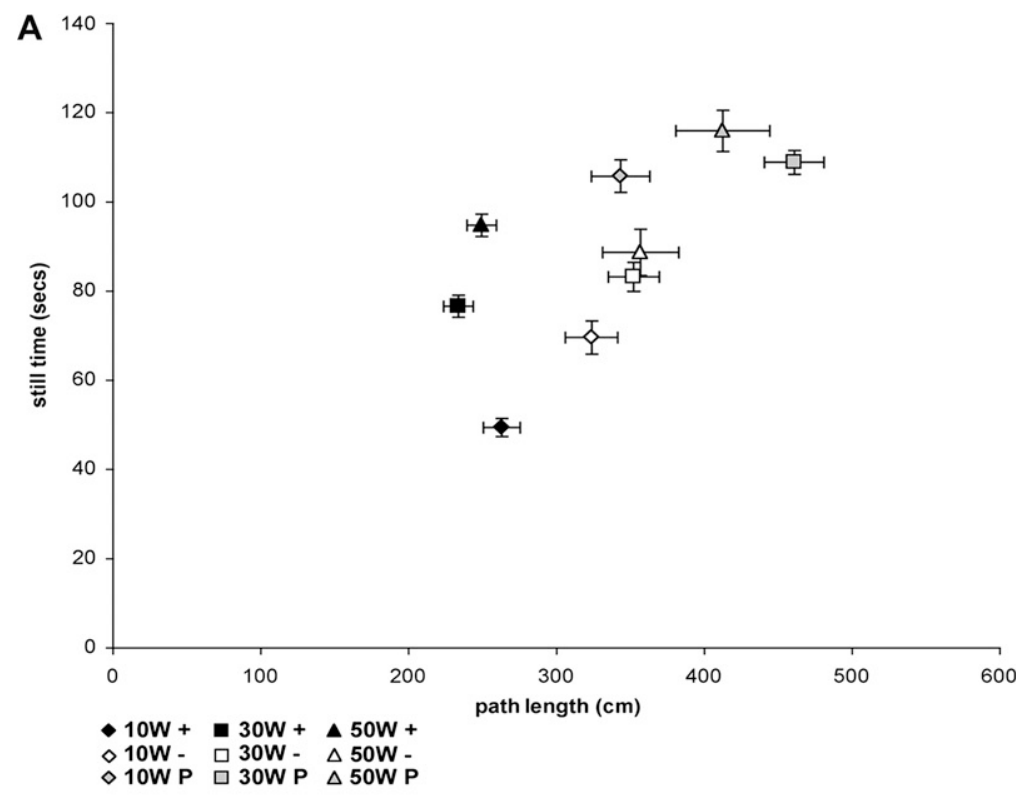

\section{B Path length}
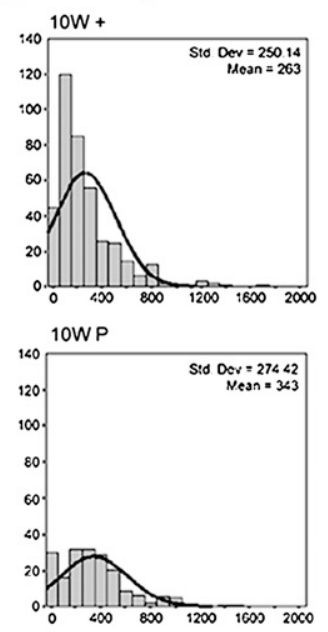

\section{Still Time}
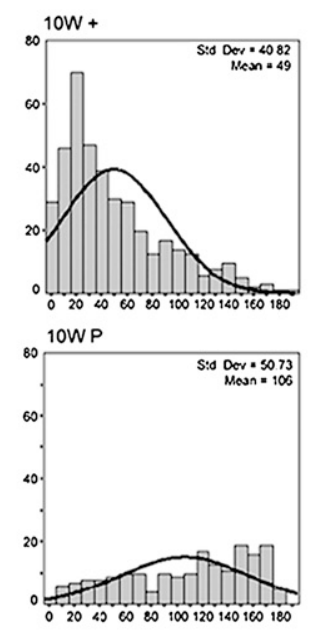
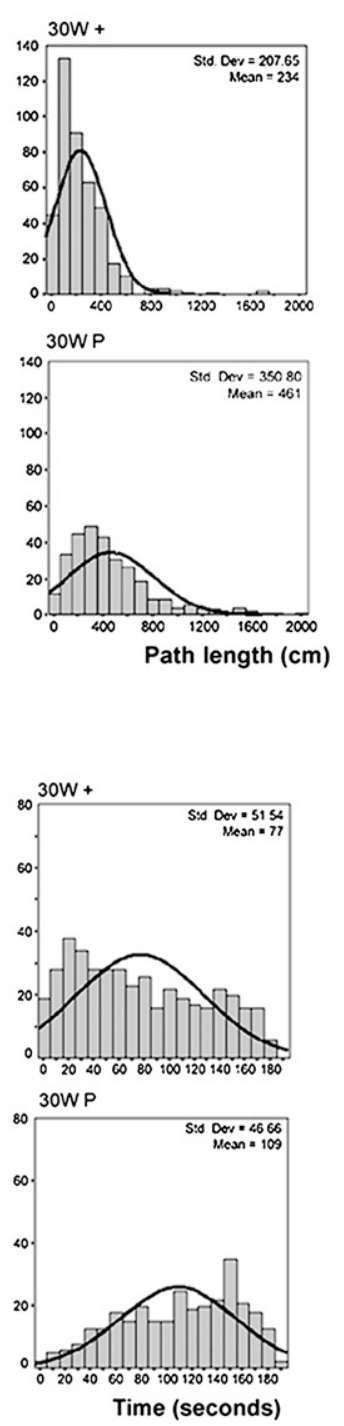

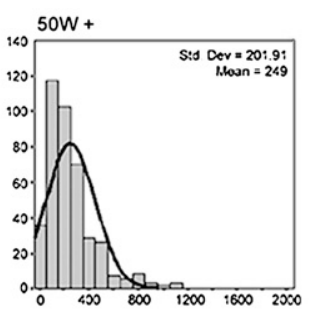

$50 W P$

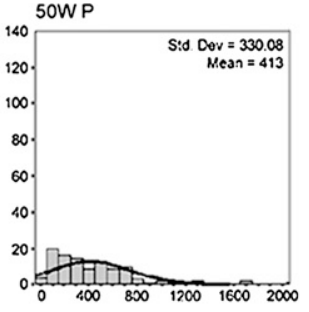

Figure 6. (Legend on next page)

decorate their axon-like processes. These spicule and varicose swellings are demonstrated by electron microscopy to represent respectively, post- and presynaptic sites. The former are characterized by electron dense thickenings opposite presynaptic specializations in the latter, which contains prominent mitochondria, presynaptic electron densities, and associated synaptic vesicles.

Golgi impregnations of mushroom body intrinsic neurons in the beta lobes show morphological differences between the age groups (refer to Fig. 8W,X). To assess these structural differences, naïve volunteers were presented with a series of images from 10-wk-old and 50-wk-old animals and asked to classify the images into groups reflecting morphological similarities and differences. Volunteers classified images into two separate groups. On average, $80.83 \%$ ( \pm SE 6.02 ) of the images from the 10 -wk-old adults were classified as one group, and $81.81 \%$ ( \pm SE 3.86) of images from the 50-wk-old adults were classified as a second group. Individual images that were consistently not placed into their relevant age-based category likely represent the biological variation to be expected both within and between age groups.

Golgi impregnations of mushroom bodies from the three age groups further reveal that Kenyon cell axons of 30-wkold and 50-wk-old adults have a significantly greater spine density than axons at the same depth and lamina of the mushroom bodies of 10-wk-old adults (Fig. 9A; $F=35.700, \mathrm{df}=479, P<0.001)$. The $10-$ wk-old adults have significantly less varicosities than all other age groups analyzed (Fig. 9B; $F=22.106$, df $=479, P<$ $0.001)$. When the combined density of spines and varicosities is compared between age groups, 10-wk-old adults had significantly lower combined densities than 50-wk-old adults, and there was no significant difference between 30-wk-old and 50-wk-old adults (Fig. 9C; $F=9.673$, $\mathrm{df}=479, P<0.001)$.

Kenyon cells of 10-wk-old adults (Fig. 8W) project approximately parallel to each other and have significantly fewer troughs and peaks (changes in contour) than do 50-wk-old adults (Fig. 9E; $t=-22.755$, df $=318, P<0.001$ ). Individual Kenyon cell processes of 50wk-old adults have more than twice the number of troughs and peaks as those of 10 -wk-old adults (Fig. 9E; mean \pm SE for 10 -wk-old, $3.86 \pm 0.115$, and 50-wk-old adults, $9.56 \pm 0.223$ ). The 10 -wk-old adults have significantly less curvature per length of axon compared with axons of 50-wk-old adults (Figs. 8W, X and 9D; $t=$ $30.656, \mathrm{df}=2153, P<0.001)$. Conversely, 
axons of 50-wk-old adults have a mean radius of curvature more than three times smaller than that of 10 -wk-old adults (Fig. 9D; mean \pm SE for 10-wk-old, $0.7365 \pm 0.0206$, and 50-wk-old adults, $0.02392 \pm 0.0061$ ). These significant differences between the age groups confirm the subjective impressions that Kenyon cell processes of 50-wk-old adults are more convoluted and tortuous than those of the 10-wk-old adults.

The structures of the spines of Kenyon cell axons of young and aged animals also differ. Spines decorating the axons of 10-wk-old adult Kenyon cell axons have uniform sizes and shapes (Fig. 8E-J). Those of 50-wk-old adults are elongated and have a variety of sizes and shapes (Fig. 8Q-V).

Ultrastructural observations (Fig. 10) support the differences in Kenyon cell organization between young and aged adults (Fig. 10A-C). Cross-sections of the lobes of 10-wk-old and 30-wk-old adults show a neat parallel arrangement of Kenyon cell axons (Fig. 10A,B). In contrast, Kenyon cell organization of the 50-wk-old adults is very different (Fig. 10C). Profiles are larger in diameter, and many are seen as oblique profilesmeaning that they are no longer arranged strictly parallel (Fig. 10A,B). Their cellular contents also differ. Cytoskeletal profiles (neurotubuli and neurofibrillae) appear diffuse in the 50-wk-old adults but not in 10-wk-old or 30-wk-old ones. Mitochondria are strikingly larger in aged animals than in the younger age groups (Fig. 10C,L,N). Mitochondrial diameters are on average $<500 \mathrm{~nm}$ in 10-wk-old adults $(345.45 \mathrm{~nm} \pm 122.89 \mathrm{~nm})$, and most are $500 \mathrm{~nm}$ or less in diameter in 30-wk-old adults (Fig. 10B,H). Mitochondria of 50-wk-old adults are at least three times as wide, and many were also observed to be undergoing fusion or division (Fig. 10K), while others appear fragmented (Fig. 10M). Other synaptic differences were also suggested between the age groups. In 10-wk-old adults, synapses with more than one presynaptic ribbon apposed to a single postsynaptic electron density, and numerous vesicles were aligned long the synaptic densities in both profiles, suggesting reciprocal communication (Fig. 10D-G). These configurations were never observed in 30-wk-old and 50-wk-old adults, where synapses were invariably polarized: one membrane density associated with vesicles, the opposing one not (Fig. $10 \mathrm{C}, \mathrm{H}, \mathrm{J}, \mathrm{L}, \mathrm{N})$. Synapses in 50-wk-old adult beta lobes were notice- ably smaller and less frequently observed than in other age groups (Fig. 10C,L,N).

\section{The central complex shows no age-related change}

Are age-related changes in structure and synaptology typical of the mushroom bodies alone or also of other higher centers? The central complex is a higher center in insects that has been implicated in the control of complex motor actions, such as directional walking and stridulations (Strauss 2002; Hoffman et al. 2007) as well as certain types of visual memory (Homberg 2008; Wang et al. 2008). Lesions of the central complex result in ataxia, as occurs after lesions of the mammalian cerebellum, and, as in aged mammals, locomotion becomes impaired in aged cockroaches (Ridgel et al. 2003; Ridgel and Ritzmann 2005). Given these manifestations of pathology and aging, it might be expected that there would be associated structural changes in central complex neuropil. However, whereas the mushroom body neuropil reveals structural and ultrastructural differences between young and aged adults, no such differences were apparent between these age groups in the central body complex (cf. Figs. 10 and 11). 


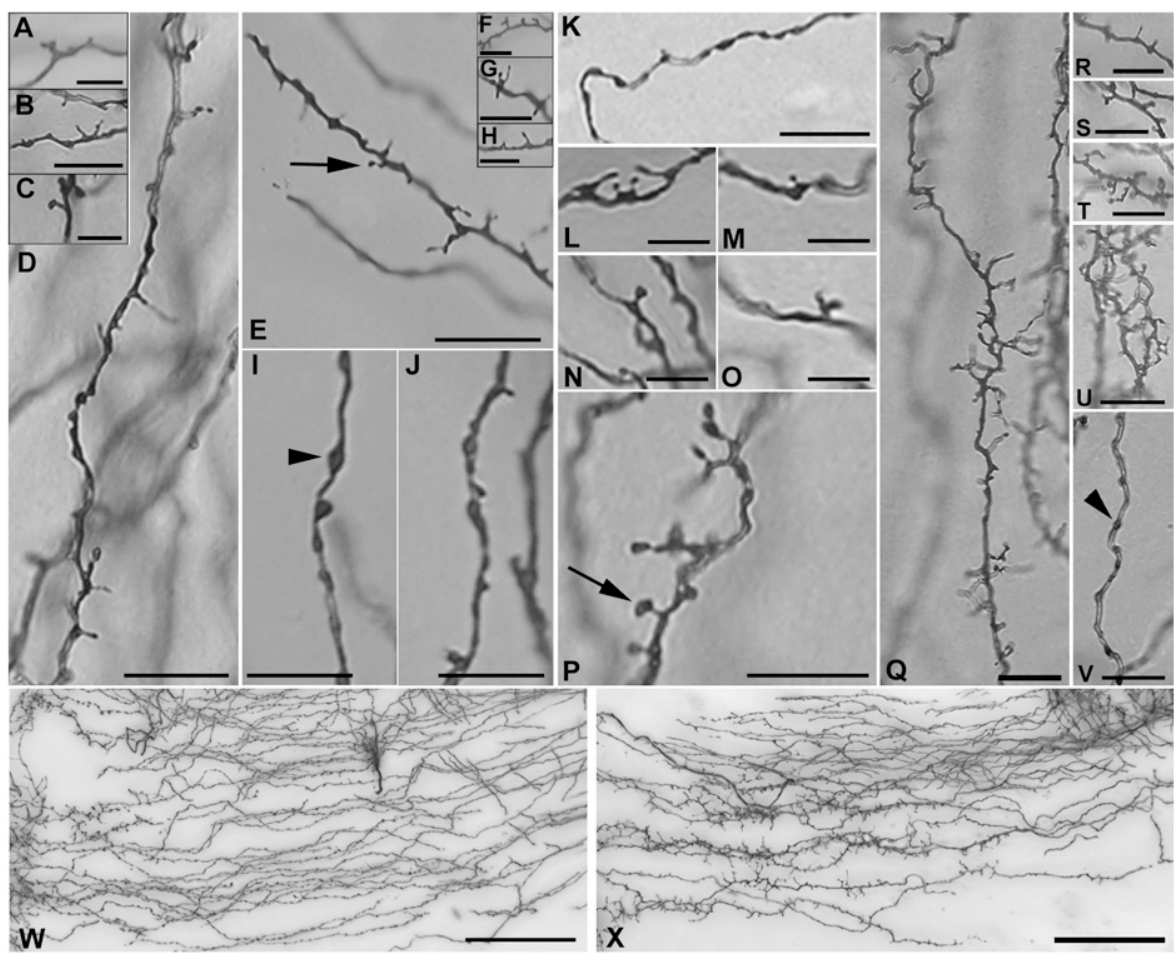

Figure 8. Golgi preparations of the mushroom body beta lobes revealed differences in the arrangement of Kenyon cell processes between young and aged cockroaches. Spines were defined as extensions (various sizes and shapes) of Kenyon cell processes that had an obvious neck (e.g., arrow in $E, P$ ). Varicosities (blebs) were defined as expansions of Kenyon cell processes without an obvious neck region (e.g., arrowhead in $I, V)$. ( $A-D$ ) Examples of a Kenyon cell process and spines from a newly eclosed adult (1-d old). Spines and varicosities were numerous. (E-J,W) Examples from a 10-wk-old adult. Processes were orderly in arrangement. Spine density was significantly lower in this age group. $(K-P)$ Thirty-week-old adults appeared similar in morphology to the 10-wk-old adults; however, spine density was significantly greater in this group. $(Q-V, X)$ Fifty-week-old adults had very different Kenyon cell morphology from that of any other age group. The Kenyon cell processes appeared more tortuous in their arrangement. Spines were elongated and at times $(U)$ tangled. While spine density was significantly greater in this age group than in 10 -wk-old adults, $(V)$ some processes did not posses spines. Scale bars, $(D, E, K, P, Q, V) 1 \mu \mathrm{m} ;(A-C, F-O, R-U) 0.5 \mu \mathrm{m} ;(W, X) 5 \mu \mathrm{m}$. monkeys (Schmolesky et al. 2000), cats (Hua et al. 2006), and rats (Muir et al. 1999; Wang et al. 2006), although a body of evidence from anatomical and morphological studies of aged retinas and subcortical areas provides little explanation for many of the perceptual deficits (Wang et al. 2006). Likewise, if there are visual defects in cockroaches, these are not resolved by comparable neuroanatomical analyses of optic lobe neuropils. Reduced silver preparations of young, middle-aged, and aged animals show no evidence of degeneration, lesions, or other decrements (Fig. 7A-H). That aged cockroaches are able to perceive the visual cues provided was demonstrated convincingly by comparing behavioral abilities of animals exposed to these cues with those that were blinded. The 50-wkold animals significantly outperformed those that had their eyes and ocelli occluded.

Cockroaches use vision for finding their way about (Kelly and Mote 1990) and directing their antennae (Ye et al. 2003). However, because it is a nocturnal insect, Periplaneta is not usually considered to have a strong reliance on vision even though it readily flies at night under conditions of high temperature and humidity. Recent studies on nocturnal carpenter bees have dispelled the myth that crepuscular or nocturnal insects with apposition eyes necessarily have poor night vision (Warrant et al. 2004). The present study clearly shows that the cockroach can and does rely on vision to navigate within its environment, although it is possible that a reliance on vision may be heightened by a reduction in olfactory and tactile information available to them in this maze task.

\section{Discussion}

A modified Barnes maze has assessed place learning and memories of juvenile, mid-life, and aged Periplaneta and has shown an agebased cognitive decline. This decline is associated with morphological alterations observed in a specific brain area that is known to support learning and memory. Comparable age-related changes were not observed in another higher center, the central body.

\section{Cockroach vision}

Paradigms previously established to study learning and memory in the cockroach and to demonstrate plasticity in the mushroom bodies have relied on antennal movements to indicate an association between visual and olfactory stimuli (Kwon et al. 2004; Lent and Kwon 2004; Lent et al. 2007). The Barnes maze is a nonolfactory-based test that relies, instead, on an association being made between the location of visual cues and an escape route from the maze to a preferred darkened area. The maze uses the cockroaches' innate negative phototaxis and is unbiased with regard to the stamina of aged cockroaches or damaged mechanosensory appendages (antennae). However, might visual acuity be reduced in the aged cockroach? Visual abilities decline during normal aging in humans (Haegerstron-Portnoy et al. 1999),

\section{Comparison of behavioral abilities of young, middle-aged, and aged cockroaches}

In both 10-wk-old and 30-wk-old age groups, those animals provided with visual cues on the walls of the maze significantly outperformed those animals not provided with proximal visual cues, in terms of both maze completion and completion consistency. Successful maze completion in 30-wk-old animals not provided with visual cues is highly variable from trial to trial (Fig. 2B), with completion consistency of individuals within this group significantly less than for those provided with visual cues $(30 \mathrm{~W}+)$. This suggests that the proximal visual cues aid these middle-aged animals in learning and task retention compared with animals not provided with proximal cues. While many 30wk-old individuals are able to perform the maze task as competently as those within 10-wk-old groups, a split in behavioral capabilities appears within the 30W+ group (Fig. 3D), suggesting that the time frame of behavioral decline within this middle-aged group can vary between individuals. The decline in the number of older individuals able to consistently complete the task over time indicates a decreased learning ability and/or memory retention from trial to trial in aging cockroaches. Data from the 50-wk-old animals $(50 \mathrm{~W}+, 50 \mathrm{~W}-)$ do not share the same trends of maze completion as in the younger age groups (Fig. 2C). In this age 

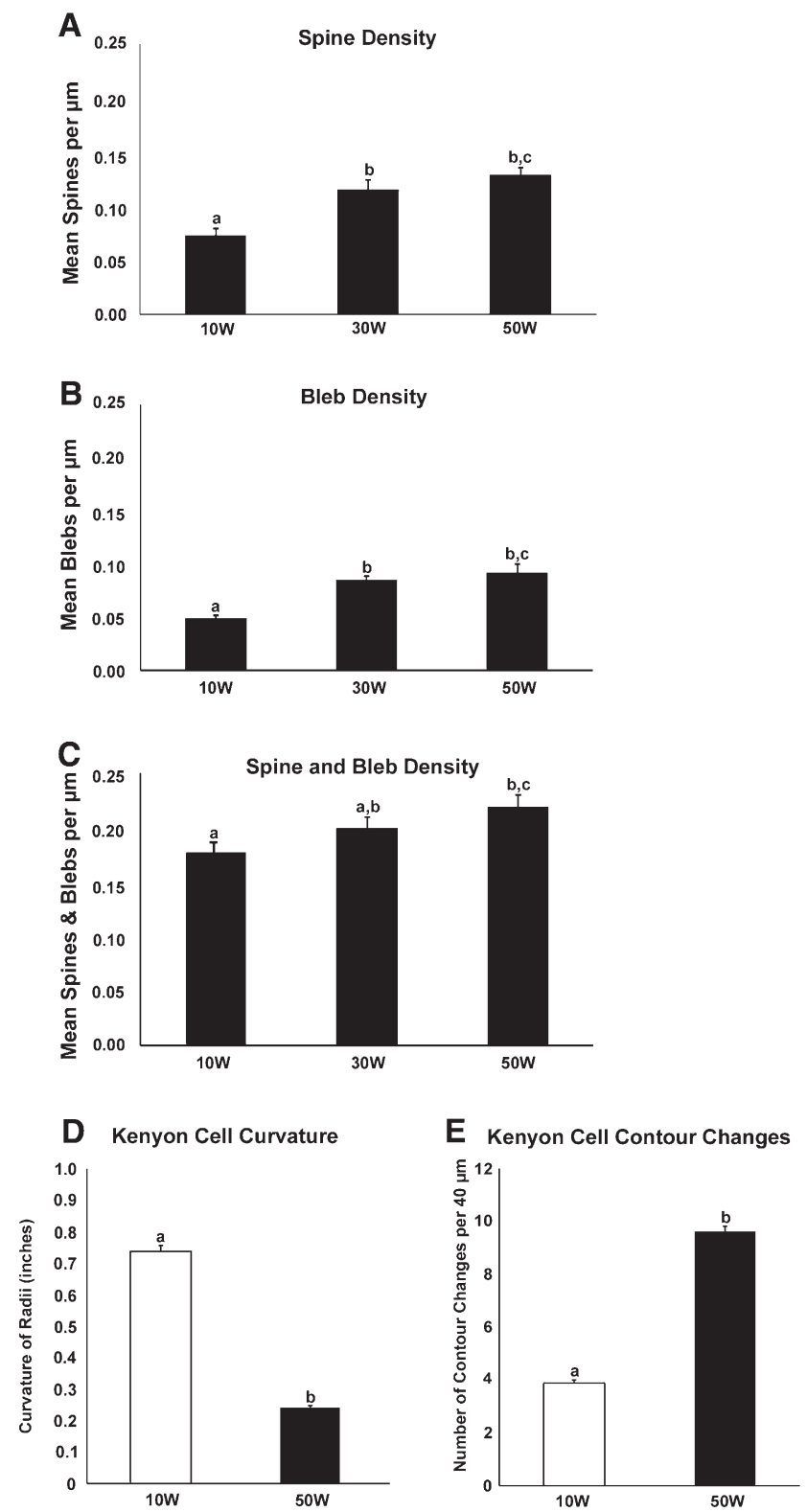

Figure 9. Spine and varicosity (bleb) density of Kenyon cell processes within the beta lobe were quantified for 10-wk-old adults (10W), 30-wkold adults (30W), and 50-wk-old adults (50W). Different letters represent significant differences between the age groups. ( $A$ ) Significantly lower spine densities were found in 10-wk-old adults than in all other age groups. Spine densities of 30-wk-old adults were not significantly different from that of 50-wk-old adults. (B) Varicosity (bleb) density was significantly higher in 50-wk-old adults than in 10-wk-old adults. (C) Analysis of combined spine and bleb densities revealed a significant increase between 10-wk-old and 50-wk-old adults. $(D)$ Radius of curvature was calculated along 40- $\mu \mathrm{m}$ lengths of randomly selected Kenyon cells within the beta lobe of 10-wk-old and 50-wk-old adults. Kenyon cells of 50-wkold adults had significantly smaller radii of curvature than the 10-wk-old adults, thus Kenyon cell processes of greater curvature. $(E)$ The number of peaks and troughs (contour changes) along 40- $\mu \mathrm{m}$ lengths of Kenyon cell processes were significantly more numerous in 50-wk-old adults, giving these Kenyon cell processes a convoluted appearance.

group, those animals not provided with proximal visual cues are significantly more successful than those animals provided with visual cues. This indicates that either animals in this group have developed search strategies that are used in preference to proximal visual cues or that visual input is "scrambled" in some way. The level at which this presumed loss of function occurs is unknown, but could involve dysfunction of visual pathways or loss of central processing ability. In the $50 \mathrm{~W}-$ group, the first $7 \mathrm{~d}$ of training provided very variable results in terms of successful maze completion. This contrasts to the second $7 \mathrm{~d}$ of training, where successful maze completion increased to and remained relatively constant around $70 \%$. Successful maze completion in the 50W+ group was

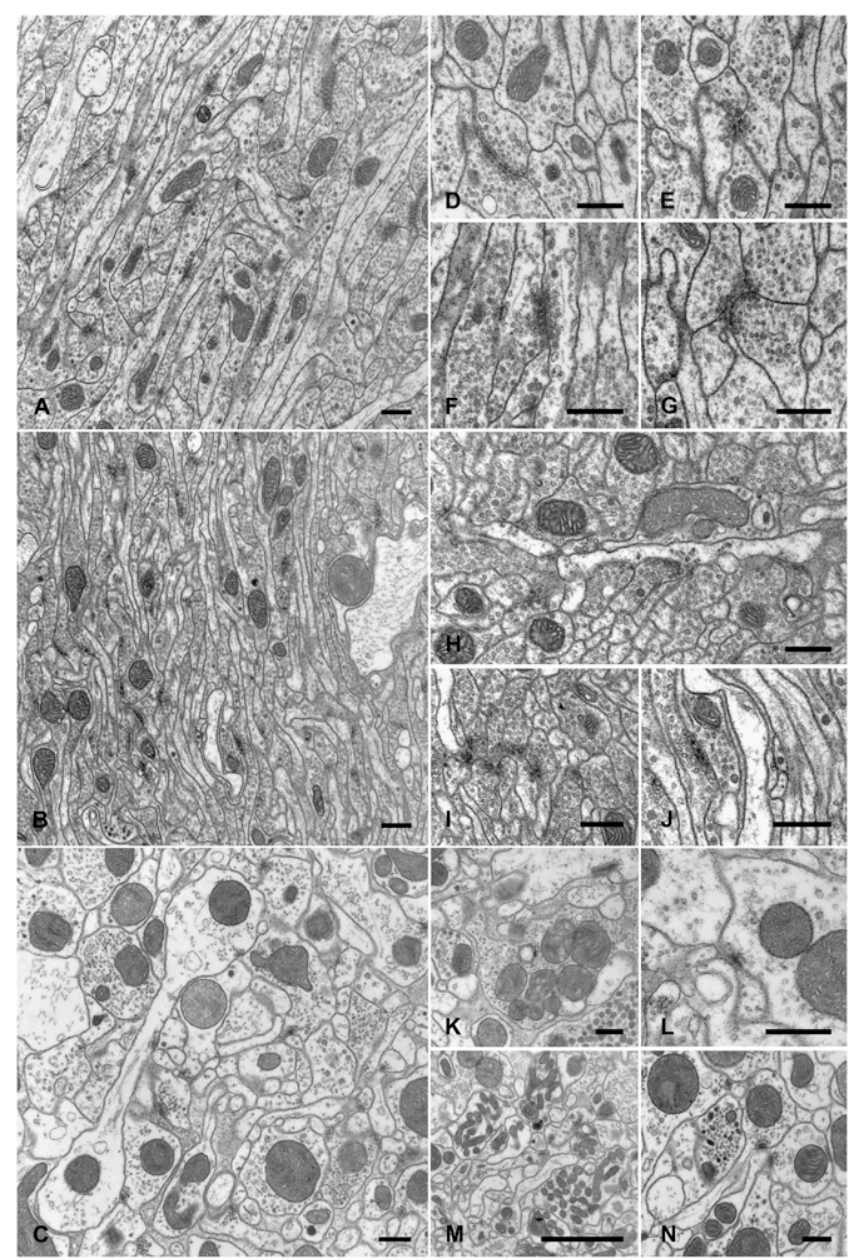

Figure 10. Ultrastructural differences of medial lobe Kenyon cells were observed between $(A, D-G) 10$-wk-old adults, $(B, H-J) 30$-wk-old adults, and $(C, K-N) 50$-wk-old adults. Tissue from all animals was cut frontally. Kenyon cells of $(A)$ 10-wk-old and $(B) 30$ wk-old adults were orderly in their arrangement with processes running parallel to each other. (C) In contrast, Kenyon cell processes from 50-wk-old animals did not display this parallel arrangement. Synapses observed in $(D-G) 10$-wk-old and $(H-$ J) 30-wk-old animals were of varying size and complexity (i.e., synapses with more than one postsynaptic component were commonly observed), and $(B-E, G-l)$ profiles were well supplied with vesicles. ( $D-G)$ Synapses with vesicles aligned both pre- and postsynaptically were commonly observed in 10-wk-old adults. In 50-wk-old adults, the synapses observed were very small and lacked complexity (usually only one postsynaptic component; see $L$ and $N) ;(L, N)$ there appeared to be less vesicles associated with individual synapses. Morphological differences of mitochondria were also observed. $(C, K, L, N)$ In 50-wk-old adults, mitochondria commonly appeared large, although cristae were still readily identifiable. (M) Alternatively, some profiles were packed with a large number of small tubular mitochondria. (H) In 30-wk-old animals, some large mitochondria were observed, but generally mitochondria observed in 10-wk-old and 30-wk-old individuals were of comparable size. Scale bars, $(A-L, N) 500$ $\mathrm{nm} ;(M) 2 \mu \mathrm{m}$. 


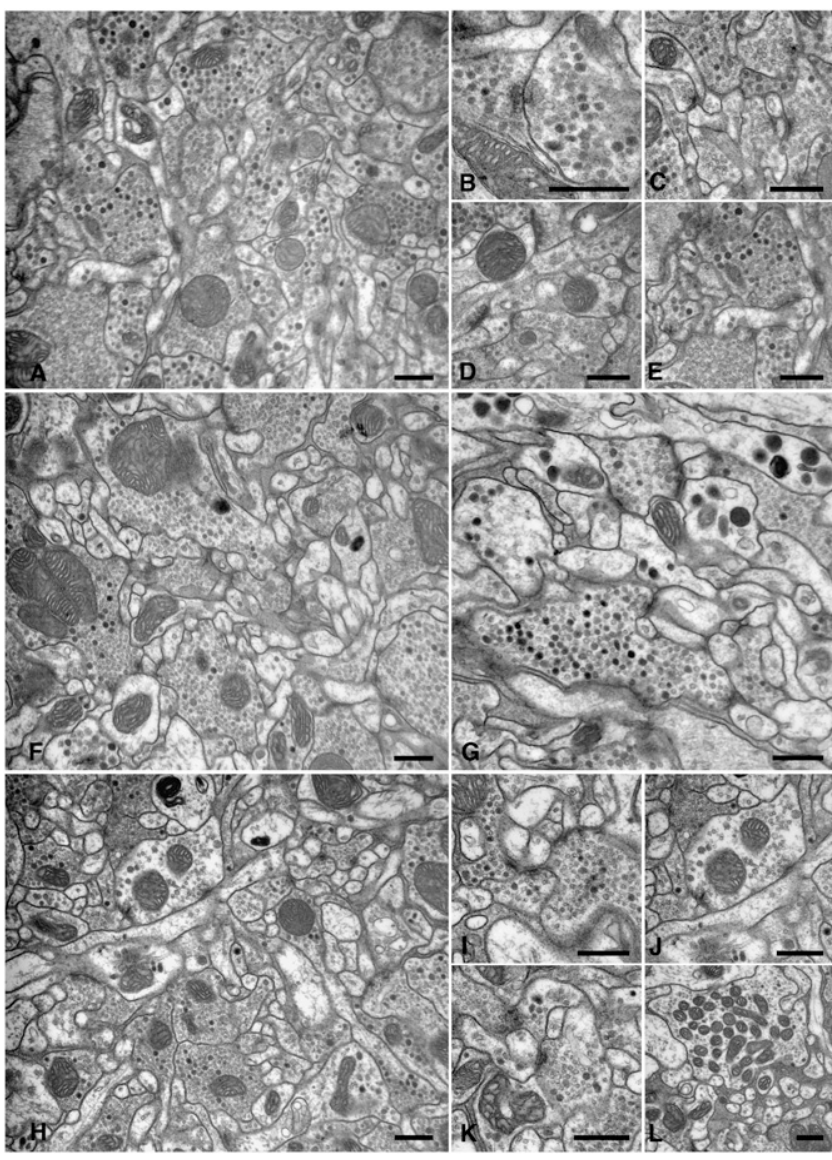

Figure 11. As a comparison to the differences observed in mushroom body ultrastructure, the central body complex in $(A-E) 10$-wk-old adults, $(F, G) 30$-wk-old adults, and $(H-L) 50$-wk-old adults was examined. $(A, F, H)$ The overall appearance of the neuropil was found to be similar across all age groups, with little evidence of differences in profile size or mitochondrial abnormalities. ( $B-E, G, I-K)$ A range of mitochondrial size was seen across all age groups, as were synapse size and complexity. While there was no evidence of oversized mitochondria in the 50 -wk-old adults, $(L)$ a small number of profiles were observed to have fragmented mitochondria. All scale bars, $500 \mathrm{~nm}$.

between $30 \%$ and $40 \%$ throughout all 14 trials. These data suggest that excess information is uninformative and may even be a source of noise or confusion to older animals. While no significant differences were evident in completion consistency between these two 50-wk-old groups, the further decline in individual consistency is pronounced in the $50 \mathrm{~W}+$ group (Fig. $3 \mathrm{G}$ ), with only $31 \%$ of the population still able to consistently complete the task in more than $50 \%$ of the trials.

In all age groups that were not provided with proximal visual cues $(10 \mathrm{~W}-, 30 \mathrm{~W}-, 50 \mathrm{~W}-)$, successful maze completion was achieved by a majority of individuals by the fourteenth trial. It is therefore important to note that although the maze itself was surrounded by black curtains to control for the impact of distant cues within the testing room, the position of the overhead camera and lights could have been used by individuals in order to aid finding the correct escape location. It has been shown in mice (Harrison et al. 2006) that the Barnes maze can be solved efficiently using either distant or proximal cues or by using a serial search strategy. In rats, distant and proximal cues are routinely used separately or in combination to differentiate the effects of aging from pathological conditions affecting spatial learning and memory (Carman and Mactutus 2001). It is thus interesting that different behavioral abilities and learning rates are also evident when cockroaches are presented with proximal cues, as opposed to when presented solely with distant cues, located outside of the maze arena.

\section{Aging and the mushroom body}

Analyses of Kenyon cell processes within the beta lobes reveal that aged cockroaches (50-wk-old) had almost twice the spine density of young (10-wk-old) adult cockroaches. In the vertebrate central nervous system, while age-associated alterations in dendritic branching and spine density have been shown to be region specific (for review, see Burke and Barnes 2006), studies have consistently shown either no significant change in spine density or a significant decrease in spine density associated with nonpathological aging (for review, see Dickstein et al. 2007). While an increase in spine density is a less common outcome of disease or injury, it does occur (Fiala et al. 2002). In many brain regions, normal development involves an increase in synapses followed by pruning to mature levels. This process may underlie results from the present study, where spine density increased significantly from 10 -wk-old adults, to 30-wk-old and 50-wk-old adults. As suggested by Fiala et al. (2002), disruption of the pruning stage may be a route to increased spine density. A balance between spine elimination and spine growth determines the net change in spine number. As the brain matures, spine stability is achieved by a slowdown in the rate of spine elimination, while spine plasticity continues to be altered by sensory stimulation and sensory deprivation (Alvarez and Sabatini 2007). In aged cockroaches, it may be that the processes of spine elimination have significantly slowed, while the long, thin spines characteristic of this age group continue to actively sample their local surroundings for appropriate contact partners, giving the processes a random or "untidy" appearance. Further ultrastructural analyses are needed to assess if these spines are usually or rarely equipped with intact synapses.

The significant differences in spine and varicosity density between young and aged cockroaches illustrate potential agerelated changes in input to and output from the mushroom body neurons. Whether these morphological changes are the cause or the consequence of decreased cognitive abilities is unknown. However, putative mechanisms underlying these changes could be based on an inability to maintain calcium homeostasis (Foster 2007), as one function of spines includes the compartmentalization of calcium ions and other signaling components (Fiala et al. 2002; Burke and Barnes 2006).

Naïve volunteers reliably assessed differences in Kenyon cell morphology within the beta lobes, where the majority of presented images could be classified into their respective age groups. This analysis, which is further supported by significant differences in spine number and Kenyon cell curvature in aged cockroaches, provides evidence that Kenyon cell morphology changes during the aging process and thus emphasizes the mushroom body lobes as targets for further ultrastructural studies.

The characteristic parallel arrangement of Kenyon cell processes within the medial lobes of the mushroom bodies is drastically disrupted during the aging process. That 50-wk-old adults have a significantly greater spine count but noticeably different synapse morphology and apparent frequency, provides strong evidence that not all spines are equipped with functional synapses in this age group. Disruptions to the structure and function of neuronal mitochondria in association with the aging process have been widely reported (for review, see Lin and Beal 2006; Terman et al. 2006; Detmer and Chan 2007; Morrow and Tanguay 2008). Specifically, an increase in the size of mitochondria during aging has been suggested to be a consequence of an imbalance between the fusion and fission events that normally 
occur to control length, size, shape, and number of mitochondria (Bossy-Wetzel et al. 2003; Detmer and Chan 2007). This imbalance can result in extremely large mitochondria because of an increase in fusion rates (Terman et al. 2006; Morrow and Tanguay 2008), or conversely a low fusion-to-fission ratio can result in numerous rod-shaped, fragmented mitochondria (Detmer and Chan 2007). Here, examples of both of these types of mitochondrial disruptions are evident in the mushroom body neuropil of 50-wk-old adults.

\section{Plasticity of the aging brain}

Several studies suggest similarities between insect and mammalian brain organization, both at the cellular and functional architectural levels (for review, see Farris 2008). Specifically, analogies have been drawn between the olfactory processing circuitry of vertebrates and invertebrates (Shepherd and Greer 1998; Strausfeld and Hildebrand 1999), and between the hippocampus and the invertebrate mushroom bodies in so far as both of these structures may play similar roles in certain types of learning and memory (Mizunami et al. 1993; de Belle and Heisenberg 1994; Muller 1996; Zars et al. 2000; McGuire et al. 2001).

A decline in cognitive abilities is typical of the aging mammalian brain. Studies on the effects of aging in the rat hippocampus have revealed that aged rats show deficits in the storage and retrieval of information about the spatial organization of their environment (Rosenzweig and Barnes 2003). A similar pattern of impairment has been found in aged mice (Bach et al. 1999), nonhuman primates (Rapp et al. 1997), and humans (e.g., Uttl and Graf 1993; Wilkniss et al. 1997; Newman and Kaszniak 2000; Moffat et al. 2001). It has also been shown that given a complex enough task, old individuals require more practice than young individuals to perform equivalently, or, given the same number of trials, they do not perform as reliably (Barnes 1979). Our study has clearly established comparable differences in the behavioral abilities of young and aged insects. That the common ancestor of the rat and roach lived $\sim 540$ mya suggests that such an age-dependent decrement is either fundamental to all nervous systems or, because analogous brain regions underlie these changes, such modifications exemplify parallel evolution of brain function. Future studies that resolve gene expression associated with the aging mushroom bodies and the aging hippocampus may resolve this intriguing question.

\section{Materials and Methods}

\section{Cockroaches}

Cockroaches (P. americana) were raised in the laboratory under a $12 / 12$-h light/dark cycle at $25^{\circ} \mathrm{C}$. Newly eclosed adults were removed from the rearing cages each week and housed separately, ensuring that all adults used in experiments were of a known age. Adult Periplaneta have a maximum life span of $64 \mathrm{wk}$, with $50 \%$ of the population dead by $56 \mathrm{wk}$ (Ridgel et al. 2003). Therefore, 30wk-old adults have lived $\sim 50 \%$ of their maximum life expectancy and were thus chosen to represent middle-aged adults. A 20-wk time interval above and below this 30 -wk time point $(10 \mathrm{wk}$, $\sim 20 \%$ of their maximum life expectancy; and $50 \mathrm{wk}, \sim 80 \%$ of their maximum life expectancy) was chosen to represent young and aged cockroaches, respectively. As such, newly eclosed adults were housed for 10,30 , and 50 wk before behavioral testing, as described below. Before testing, animals were re-conditioned to a 12/12-h dark/light cycle, to ensure they were at their most active during testing.

\section{Behavioral procedures}

Animals were tested on a modified Barnes maze (Barnes 1979). This comprised a 12-inch diameter circular aluminum platform, enclosed by a 10-inch wall (Fig. 1A). Eight potential escape tunnels were spaced equidistant around the perimeter of the platform, affixed through the lower edge of the wall. All tunnels were made of identical PVC material; seven were blind ending, while one tunnel led away from the platform into a 7.2-inch length by 4.2inch width by 5.5 -inch height container (Fig. 1B). To aid location of the escape tunnel, visual cues were placed at four locations on the maze wall; vertical black lines paired with an ultraviolet LED $(405 \mathrm{~nm})$ at the escape tunnel entrance, horizontal black lines $180^{\circ}$ from the escape tunnel, diamond patterns paired with a blue LED $(430 \mathrm{~nm}) 90^{\circ}$ clockwise from the escape tunnel, and an irregular star shape paired with a green LED (565 nm) $90^{\circ}$ anticlockwise from the escape tunnel. Previously reported angles of acceptance for $P$. americana ommatidia (Butler and Horridge 1979) were used to determine the necessary width $(1.9 \mathrm{~cm})$ of stripes comprising horizontal and vertical grating patterns. To increase motivation to locate the correct escape tunnel, two $125 \mathrm{~W}$ infrared heat lamps were aimed at the maze surface in such a way as to avoid shadows. Temperature at the platform surface was consistently measured at $35^{\circ} \mathrm{C}$ at both the outer and inner regions. All animals were given a maximum of 3 min to locate and enter the correct escape tunnel. Those individuals that did not successfully complete the task within this time frame were removed from the maze and their trial marked unsuccessful. All trials were recorded using a Sony videocamera, positioned directly above the maze and focused onto the platform surface. Digital recordings were stored directly onto a computer using Virtual VCR, for later analysis.

Before testing began, all animals were placed onto the maze, under red light conditions, for an adaptation period of 30-60 min. During this time, individuals were free to explore the platform and tunnels, and food was placed into the holding container to ensure that individuals were motivated to locate and move through the correct escape tunnel. Animals were tagged with a small numbered disc to their thorax, thus ensuring that individuals were uniquely identifiable throughout the testing period. Testing consisted of removing animals from their communal cages and placing them individually in small containers, from which each animal was placed onto the central point of the maze platform in a random orientation. As soon as the animal was standing on the platform surface, the small container was removed, allowing the animal to move freely. Animals were tested one time per day, for 14 consecutive days. The number of trials used was determined from a pilot study showing while aged cockroaches had low maze completion rates, they did show slight improvement after seven trials; it was therefore thought that a total of 14 trials would provide sufficient time for all cockroaches to learn the maze task to the best of their capabilities. On day 15 , all visual cues were rotated $90^{\circ}$ clockwise, while the escape tunnel remained in its original position. Testing was designed to determine if the animals had learned the position of the escape tunnel in relation to the placement of the visual cues. In order to eliminate as much as possible a reliance on olfactory cues, all maze surfaces including blind ending tunnels were cleaned with ethanol after each animal had been tested. The small container and escape tunnel were replaced and cleaned after each trial. All blind-ending tunnels were routinely rotated to a different location within the maze to avoid any reliance on tactile cues. After each trial, animals were returned to their communal cages and held until the following trial.

To assess the role of the visual cues provided on the walls of the maze, a second group of animals that were not provided with visual cues $\left(10 \mathrm{~W}_{-}, 30 \mathrm{~W}_{-}\right.$, and $\left.50 \mathrm{~W}_{-}\right)$) were tested one time per day over 14 consecutive days. To assess the general role of vision in this maze task, a third group of animals had their eyes and ocelli covered with paint (10W P, 30W P, and 50W P), and were also tested one time per day for 14 consecutive days.

\section{Data analysis}

All digital recordings were converted to AVI files and batch processed through an auto-tracking program written in MATLAB (The Mathworks Inc.) whereby the location of the cockroach on the maze platform was automatically tracked frame by frame. The 
output provided a distance (in centimeters) and a location map of the cockroach moving from the central point of the maze to the endpoint during the 3-min test period. From these data, speed (in centimeters per second), still time (in seconds), moving time (in seconds), and completion time (in seconds) were calculated for all individuals over all tests. Digital recordings were viewed and scored as to how many times an individual cockroach tried to escape the maze platform using one of the blind-ending tunnels (number of errors).

Statistical analyses of maze completion (Fig. 2), completion consistency (Fig. 3), completion time, and number of errors (Fig. 4), were performed using SPSS statistical software (SPSS Inc.). Oneway ANOVA in conjunction with post hoc Tukey's tests were used to detect differences in parametric data, at the 0.05 level.

A logistic regression using generalized estimating equation (GEE) methodology was used to identify interactive effects of the measured parameters (Table 1). A GEE modeling approach was used instead of standard logistic regression to account for autocorrelation of the data across time. This analysis was performed using SAS statistical software (The SAS Institute, Cary, NC).

\section{Histology}

Reduced silver-stained tissue (Fig. 7A-H) was used to examine the optic lobe neuropils in young, middle-aged, and aged cockroaches to check for any gross neuroanatomical deformities. Brains were dissected and fixed in AAF (85 parts 95\% ethanol, 10 parts 35\% formalin, 5 parts glacial acetic acid) at room temperature. Brains were dehydrated, cleared, and embedded in Paraplast (Oxford Labware) and sectioned at $12 \mu \mathrm{m}$. Reduced silver staining was performed according to Bodian's (1936) original protocol.

A combined Colonnier/rapid Golgi staining protocol (Li and Strausfeld 1997; Farris and Strausfeld 2001) was used to stain individual Kenyon cells in cockroach mushroom bodies. Observations of the Golgi preparations showed apparent differences in the organization of the Kenyon cell processes between the age groups (Fig. 8). To assess these differences, low power images (40× objective) from these same Golgi preparations were then presented to six naïve observers. Two images were collected from each animal, from two sections containing the beta lobe neuropil. Approximately the same depths within the beta lobe neuropil were located for each individual. At $40 \times$ magnification, the entire beta lobe neuropil is represented within the collected image. The aim was to determine if a collective group of images comprising beta lobe Kenyon cells from 10-wk-old and 50-wk-old individuals could be classified into their respective age groups, based purely on their morphological characteristics.

The Golgi stained preparations were then used to quantify the linear density of varicosities and spines on Kenyon cells within the beta lobes of 10-wk-old, 30-wk-old, and 50-wk-old adult cockroaches ( $n=10,12,11$, respectively; Fig. 9A-C), and also the curvature of Kenyon cell processes within the beta lobes (Fig. $9 \mathrm{D}, \mathrm{E})$. Approximately the same region was located within the beta lobes for each individual and examined with a $100 \times$ objective using a Leitz Diaplan microscope and projected onto a monitor using a Sony DC 5000 digital camera. Individual Kenyon cells were chosen for analysis randomly from the field of view by overlaying the monitor screen with a transparent grid $\left(30 \mu \mathrm{m}^{2}\right)$ and selecting 1 grid square by way of a random numbers table. To quantify spines and varicosities, Kenyon cell processes visible within this grid square were followed through the tissue as far as possible and traced onto an overlaying sheet of mylar film, and the number of associated spines and varicosities per process was recorded. The length of each process was calculated using a Scale Master Classic digital plan measure (Calculated Industries, Inc.), thus ensuring that accurate estimates of spine and varicosity densities were calculated (Fig. 9). All preparations were re-coded prior to analysis to ensure blind testing. A total of 16 Kenyon cell processes from within two histological sections were analyzed per animal. Oneway ANOVA in conjunction with post hoc Tukey's tests were used to detect differences at the 0.05 level, using SPSS software. Curvature of Kenyon cell processes within the beta lobes was then quantified in 10-wk-old $(n=10)$ and 50-wk-old $(n=10)$ adults. A total of 16 Kenyon cell processes, each $40 \mu \mathrm{m}$ in length, were randomly selected from within two histological sections per animal. Curvature was measured at every contour change along the length of the process being analyzed. Curvature can be quantified by placing a circle over the region under examination so that the circle just fits the curve at a given point. The radius of the circle is the radius of curvature, and thus the smaller the radius, the greater the curvature. The number of contour changes (peaks and troughs) along the length of individual processes was also compared between 10 -wk-old and 50 -wk-old adults. $t$-Tests were used to detect differences at the 0.05 level, using SPSS software.

\section{Electron microscopy}

Light microscope observations of Kenyon cell organization and spine quantification prompted a preliminary ultrastructural analysis. Brain tissue was fixed using $4 \%$ paraformaldehyde, $2 \%$ glutaraldehyde in $0.1 \mathrm{M}$ cacodylate buffer $(\mathrm{pH} 7.4)$, and held overnight at $4^{\circ} \mathrm{C}$. After primary fixation, samples were washed several times in cacodylate buffer and post-fixed in $1 \% \mathrm{OsO}_{4}$ solution in cacodylate buffer for $2 \mathrm{~h}$ at room temperature. The tissue was then rinsed through several buffer changes, stained en bloc by using $2 \%$ uranyl acetate solution in distilled water for $1 \mathrm{~h}$, dehydrated through a graded ethanol series, and embedded in Embed 812 epoxy resin (EMS). Blocks were polymerized for $48 \mathrm{~h}$ at $60^{\circ} \mathrm{C}$. Semithin sections $(1.5 \mu \mathrm{m})$ and ultrathin sections $(80 \mathrm{~nm})$ were cut on a Leica Ultracut $S$ Ultramicrotome. Ultrathin sections were collected on formvar-coated copper slot grids. Sections were post-stained with uranyl acetate and lead citrate. The sections were then viewed and photographed in a JEOL 1200 EX transmission electron microscope.

\section{Terminology}

Within the mushroom bodies, Kenyon cell axons comprise the medial lobes, the vertical lobes, and the lobelet (only the medial lobes are considered here). The medial lobes are subdivided into discrete divisions: the beta and gamma lobes. Because in this study we wanted to distinguish regions within the medial lobes, we have used the beta terminology.

\section{Acknowledgments}

Special thanks to Reina Estrada for assisting with the behavioral experiments; Mike Zimmerman for providing the Bodian and Golgi preparations shown in Figures 7 and 8; Angelique Paulk for providing the Matlab autotracking program and ongoing advice on its use; and Mark Borgstrom for statistics advice and performing the GEE analysis. Funding was provided by the New Zealand Foundation of Research, Science and Technology.

\section{References}

Alvarez, V.A. and Sabatini, B.L. 2007. Anatomical and physiological plasticity of dendritic spines. Annu. Rev. Neurosci. 30: 79-97.

Bach, M.E., Barad, M., Son, H., Zhuo, M., Lu, Y.F., Shih, R., Mansuy, I., Hawkins, R.D., and Kandel, E.R. 1999. Age-related defects in spatial memory are correlated with defects in the late phase of hippocampal long-term potentiation in vitro and are attenuated by drugs that enhance the cAMP signaling pathway. Proc. Natl. Acad. Sci. 96: 52805285

Barnes, C.A. 1979. Memory deficits associated with senescence: A neurophysiological and behavioral study in the rat. J. Comp. Physiol. Psychol. 93: 74-104.

Barnes, C.A. 1994. Normal aging: Regionally specific changes in hippocampal synaptic transmission. Trends Neurosci. 17: 13-18.

Besson, M. and Martin, J.R. 2005. Centrophobism/thigmotaxis, a new role for the mushroom bodies in Drosophila. J. Neurobiol. 62: 386-396.

Bodian, D. 1936. A new method for staining nerve fibers and nerve endings in mounted paraffin sections. Anat. Rec. 65: 89-97.

Bossy-Wetzel, E., Barsoum, M.J., Godzik, A., Schwarzenbacher, R., and Lipton, S.A. 2003. Mitochondrial fission in apoptosis, neurodegeneration and aging. Curr. Opin. Cell Biol. 15: 706-716.

Burke, S.N. and Barnes, C.A. 2006. Neural plasticity in the ageing brain. Nat. Rev. Neurosci. 7: 30-40. 
Butler, R. and Horridge, G.A. 1979. The electrophysiology of the retina of Periplaneta americana L. 1. Changes in receptor acuity upon light/dark adaptation. J. Comp. Physiol. 83: 263-278.

Carman, H.M. and Mactutus, C.F. 2001. Proximal versus distal cue utilization in spatial navigation: The role of visual acuity? Neurobiol. Learn. Mem. 78: 332-346.

Davis, R.L. 2005. Olfactory memory formation in Drosophila: From molecular to systems neuroscience. Annu. Rev. Neurosci. 28: 275-302.

de Belle, J.S. and Heisenberg, M. 1994. Associative odor learning in Drosophila abolished by chemical ablation of mushroom bodies. Science 263: 692-695.

De Groot, D.M.G. and Bierman, E.P.B. 1987. Numerical changes in rat hippocampal synapses. An effect of "ageing"? Acta Stereol. 6: 53-58.

Detmer, S.A. and Chan, D.C. 2007. Functions and dysfunctions of mitochondrial dynamics. Nature 8: 870-879.

Dickstein, D.L., Kabaso, D., Rocher, A.B., Luebke, J.I., Wearne, S.L., and Hof, P.R. 2007. Changes in the structural complexity of the aged brain. Aging Cell 6: 275-284.

Duan, H., Wearne, S.L., Rocher, A.B., Macedo, A., Morrison, J.H., and Hof, P.R. 2003. Age-related dendritic and spine changes in corticocortically projecting neurons in macaque monkeys. Cereb. Cortex 13: 950-961.

Farris, S.M. 2008. Structural, functional and developmental convergence of the insect mushroom bodies with higher brain centers of vertebrates. Brain Behav. Evol. 72: 1-15.

Farris, S.M. and Strausfeld, N.J. 2001. Development of laminar organization in the mushroom bodies of the cockroach: Kenyon cell proliferation, outgrowth, and maturation. J. Comp. Neurol. 439: 331-351.

Fiala, J.C., Spacek, J., and Harris, K.M. 2002. Dendritic spine pathology: Cause or consequence of neurological disorders? Brain Res. Brain Res. Rev. 39: 29-54.

Foster, T.C. 2007. Calcium homeostasis and modulation of synaptic plasticity in the aged brain. Aging Cell 6: 319-325.

Geanacopoulos, M. 2004. The determinants of lifespan in the nematode Caenorhabditis elegans: A short primer. Sci. Prog. 87: 227-247.

Geinisman, Y., de Toledo-Morrell, L., Morrell, F., Persina, I.S., and Rossi, M. 1992. Structural synaptic plasticity associated with the induction of long-term potentiation is preserved in the dentate gyrus of aged rats. Hippocampus 2: 445-456.

Haegerstron-Portnoy, G., Schneck, M.E., and Brabyn, J.A. 1999. Seeing into old age: Vision function beyond acuity. Optom. Vis. Sci. 76: $141-158$.

Harrison, F.E., Reiserer, R.S., Tomarken, A.J., and McDonald, M.P. 2006. Spatial and nonspatial escape strategies in the Barnes maze. Learn. Mem. 13: $809-819$.

Hoffman, K., Wirmer, A., Kunst, M., Gocht, D., and Heinrich, R. 2007. Muscarinic excitation in grasshopper song control circuits is limited by acetylcholinesterase. Zoolog. Sci. 24: 1028-1035.

Homberg, U. 2008. Evolution of the central complex in the arthropod brain with respect to the visual system. Arthropod Struct. Dev. 37: 347-362.

Hua, T., Li, X., He, L., Zhou, Y., Wang, Y., and Leventhal, A.G. 2006. Functional degradation of visual cortical cells in old cats. Neurobiol. Aging 27: 155-162.

Kelly, K.M. and Mote, M.I. 1990. Avoidance of monochromatic light by the cockroach Periplaneta americana. J. Insect Physiol. 36: 287-291.

Kwon, H.-W., Lent, D.D., and Strausfeld, N.J. 2004. Spatial learning in the restrained American cockroach Periplaneta americana. J. Exp. Biol. 207: 377-383.

Lent, D.D. and Kwon, H.-W. 2004. Antennal movements reveal associative learning in the American cockroach Periplaneta americana. J. Exp. Biol. 207: 369-375.

Lent, D.D., Pinter, M., and Strausfeld, N.J. 2007. Learning with half a brain. Dev. Neurobiol. 67: 740-751.

Li, Y. and Strausfeld, N.J. 1997. Morphology and sensory modality of mushroom body extrinsic neurons in the brain of the cockroach, Periplaneta americana. J. Comp. Neurol. 387: 631-650.

Li, Y. and Strausfeld, N.J. 1999. Multimodal efferent and recurrent neurons in the medial lobes of the cockroach mushroom bodies. J. Comp. Neurol. 409: 647-663.

Lim, H.-Y., Bodmer, R., and Perrin, L. 2006. Drosophila aging 2005/06. Exp. Gerontol. 41: 1213-1216.

Lin, M.T. and Beal, M.F. 2006. Mitochondrial dysfunction and oxidative stress in neurodegenerative diseases. Nature 443: 787-795.

Masoro, E.J. 2006. Caloric restriction and aging: Controversial issues. J. Gerontol. A Biol. Sci. Med. Sci. 61: 14-19.

McGuire, S.E., Le, P.T., and Davis, R.L. 2001. The role of Drosophila mushroom body signaling in olfactory memory. Science 293: 1330-1333.

Mizunami, M., Weibrecht, J.M., and Strausfeld, N.J. 1993. A new role for the insect mushroom bodies: Place memory and motor control. In Biological neural networks in invertebrate neuroethology and robotics (eds. R.D. Beer et al.), pp. 199-225. Academic Press, Cambridge, MA.

Mizunami, M., Okada, R., Li, Y., and Strausfeld, N.J. 1998a. Mushroom bodies of the cockroach: Activity and identities of neurons recorded in freely moving animals. J. Comp. Neurol. 402: 501-519.

Mizunami, M., Weibrecht, J.M., and Strausfeld, N.J. 1998b. Mushroom bodies of the cockroach: Their participation in place memory. J. Comp. Neurol. 402: 520-537.

Moffat, S.D., Zonderman, A.B., and Resnick, S.M. 2001. Age differences in spatial memory in a virtual environment navigation task. Neurobiol. Aging 22: 787-796.

Morris, R.G., Garrud, P., Rawlins, J.N., and O'Keefe, J. 1982. Place navigation impaired in rats with hippocampal lesions. Nature 297: 681-683.

Morrow, G. and Tanguay, R.M. 2008. Mitochondria and ageing in Drosophila. Biotechnol. J. 3: 728-739.

Muir, J.L., Fischer, W., and Bjorklund, A. 1999. Decline in visual attention and spatial memory in aged rats. Neurobiol. Aging 20: 605-615.

Muller, R. 1996. A quarter of a century of place cells. Neuron 17: 813-822.

Newman, M.C. and Kaszniak, A.W. 2000. Spatial memory and aging: Performance on a human analog of the Morris water maze. Aging Neuropsychol. Cogn. 7: 86-93.

Pintér, M., Lent, D.D., and Strausfeld, N.J. 2005. Memory consolidation and gene expression in Periplaneta americana. Learn. Mem. 12: 30-38.

Rapp, P.R., Kansky, M.T., and Roberts, J.A. 1997. Impaired spatial information processing in aged monkeys with preservation recognition memory. Neuroreport 8: 1923-1928.

Ridgel, A.L. and Ritzmann, R.E. 2005. Insights into age-related locomotor declines from studies of insects. Ageing Res. Rev. 4: 25-39.

Ridgel, A.L., Ritzmann, R.E., and Schaefer, P.L. 2003. Effects of aging on behavior and leg kinematics during locomotion in two species of cockroach. J. Exp. Biol. 206: 4453-4465.

Rosenzweig, E.S. and Barnes, C.A. 2003. Impact of aging on hippocampal function: Plasticity, network dynamics, and cognition. Prog. Neurobiol. 69: $143-179$.

Saitoe, M., Horiuchi, J., Tamura, T., and Ito, N. 2005. Drosophila as a novel animal model for studying the genetics of age-related memory impairment. Rev. Neurosci. 16: 137-149.

Schmolesky, M.T., Wang, Y., Pu, M., and Leventhal, A.G. 2000. Degradation of stimulus selectivity of visual cortical cells in senescent rhesus monkeys. Nat. Neurosci. 3: 384-390.

Shepherd, G.M. and Greer, C.A. 1998. Olfactory bulb. In The synaptic organization of the brain (eds. G.M. Shepherd et al.), pp. 159-204. Oxford University Press, Oxford, UK.

Strausfeld, N.J. and Hildebrand, J.G. 1999. Olfactory systems: Common design, uncommon origins? Curr. Opin. Neurobiol. 9: 634-639.

Strauss, R. 2002. The central complex and the genetic dissection of locomotor behaviour. Curr. Opin. Neurobiol. 12: 633-638.

Terman, A., Gustafsson, B., and Brunk, U.T. 2006. Mitochondrial damage and intralysosomal degradation in cellular aging. Mol. Aspects Med. 27: $471-482$.

Uttl, B. and Graf, P. 1993. Episodic spatial memory in adulthood. Psychol. Aging 8: 257-273.

Wang, H., Xie, X., Li, X., Chen, B., and Zhou, Y. 2006. Functional degradation of visual cortical cells in aged rats. Brain Res. 1122: 93-98.

Wang, Z., Pan, Y., Li, W., Jiang, H., Chatzimanolis, L., Chang, J., and Liu, L. 2008. Visual pattern memory requires foraging function in the central complex of Drosophila. Learn. Mem. 15: 133-142.

Warrant, E.J., Kelber, A., Gislén, A., Greiner, B., Ribi, W., and Wcislo, W.T. 2004. Nocturnal vision and landmark orientation in a tropical halictid bee. Curr. Biol. 14: 1309-1318.

West, M.J. 1993. Regionally specific loss of neurons in the aging human hippocampus. Neurobiol. Aging 14: 287-293.

Wilkniss, S.M., Jones, M.G., Korol, D.L., and Manning, C.A. 1997. Agerelated differences in an ecologically based study of route learning. Psychol. Aging 12: 372-375.

Wolf, R., Wittig, T., Liu, L., Wustmann, G., Eyding, D., and Heisenberg, M. 1998. Drosophila mushroom bodies are dispensable for visual, tactile and motor learning. Learn. Mem. 5: 166-178.

Ye, S., Leung, V., Khan, A., Baba, Y., and Comer, C.M. 2003. The antennal system and cockroach evasive behavior. I. Roles for visual and mechanosensory cues in the response. J. Comp. Physiol. [A] 189: 89-96.

Zars, T. 2000. Behavioral functions of the insect mushroom bodies. Curr. Opin. Neurobiol. 10: 790-795.

Zars, T., Fischer, M., Schulz, R., and Heisenberg, M. 2000. Localization of a short-term memory in Drosophila. Science 288: 672-675.

Received October 10, 2008; accepted in revised form January 7, 2009. 


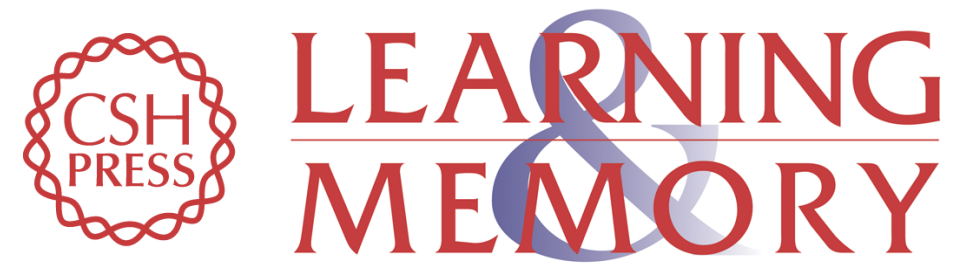

\section{The effect of age on a visual learning task in the American cockroach}

Sheena Brown and Nicholas Strausfeld

Learn. Mem. 2009, 16:

Access the most recent version at doi:10.1101//m.1241909

References This article cites 65 articles, 11 of which can be accessed free at:

http://learnmem.cshlp.org/content/16/3/210.full.html\#ref-list-1

License

Email Alerting Receive free email alerts when new articles cite this article - sign up in the box at the Service top right corner of the article or click here. 